\title{
Política fiscal y bonanza: impacto del aumento de los precios de los productos no renovables en América Latina y el Caribe
}

\author{
Juan Pablo Jiménez y Varinia Tromben
}

Juan Pablo Jiménez

Oficial de Asuntos Económicos

División de Desarrollo Económico,

CEPAL

— juanpablo.jiménez@cepal.org

Varinia Tromben

Asistente de investigación,

Área de Políticas Presupuestarias

y Gestión Pública,

Instituto Latinoamericano y del Caribe

de Planificación Económica y Social (ILPES)

œVarinia.tromben@cepal.org

n países especializados en productos no renovables, a los desafíos que usualmente enfrenta la política fiscal hay que sumar los que derivan de las características intrínsecas de estos bienes. Entre aquellos países en cuyas exportaciones la participación de productos no renovables representa más del 20\%, sobresalen Bolivia, Chile, Colombia, Ecuador, México, Trinidad y Tabago y la República Bolivariana de Venezuela. Este artículo examina la relación entre la mejora de los términos de intercambio en estos países y los desafíos a los que debe enfrentarse su política fiscal. Para ello analiza la importancia de la explotación de estos productos, pasando revista a la evolución de sus precios y a su efecto sobre los términos de intercambio. Asimismo, considera el desempeño de estos países en relación con las características más salientes de la política fiscal en la región, y analiza la evolución de las cuentas públicas ante los recientes aumentos de los precios, haciendo hincapié en su impacto y las decisiones de política adoptadas. 


\section{Introducción}

...Como sabían bien quienes en el siglo XVIII se habían inclinado sobre el enigma de ese gigantesco imperio dominado por una de las más arcaicas naciones de Europa, lo que había movido a los conquistadores era la búsqueda de metal precioso...

Halperín Donghi (1990)

América Latina y el Caribe ha sido tradicionalmente un importante proveedor de recursos energéticos y minerales. La región contribuye con el $13 \%$ del petróleo que se produce a nivel mundial y posee el $10 \%$ de sus reservas mundiales, y Chile es el primer productor y exportador de cobre, representando en promedio el $35 \%$ de la producción mundial. Por esta razón, las recurrentes fluctuaciones en los precios de estos bienes tienen un significativo impacto en las economías de los países especializados en estos productos.

Entre los numerosos dilemas que esta situación plantea, dos son las preguntas dominantes que enfrentan los hacedores de política fiscal en los períodos de auge. La primera es cómo aprovechar el aumento de los precios de estos productos en términos de ingresos fiscales y, la segunda, qué uso debiera darse a los excedentes fiscales generados para evitar los problemas macroeconómicos que suelen plantear estos períodos de bonanza.

En cuanto al primer interrogante, las herramientas que se utilicen van a depender ante todo de si la propiedad de estos recursos no renovables es pública o privada. $\mathrm{La}$ forma más directa de transformar en ingresos fiscales lo que se obtiene por la explotación de estos productos ha sido la participación de los gobiernos en su extracción a través de empresas de propiedad pública. En la medida en que sean de propiedad privada, la recaudación fiscal proveniente de estos sectores se obtiene mediante una combinación de instrumentos tributarios que gravan la explotación y comercialización de los recursos no renovables: regalías, impuestos sobre los ingresos e impuestos sobre las utilidades, aplicables a las empresas que explotan este tipo de recursos. Además, en los últimos años, coincidiendo con el significativo aumento

$\square$ Los autores agradecen los comentarios de Omar Bello, Guillermo Cruces, Osvaldo Kacef y Ricardo Martner, así como los de un juez anónimo a un texto preliminar. No obstante, todas las opiniones, errores $\mathrm{u}$ omisiones son de exclusiva responsabilidad de los autores. de los precios de estos productos, algunos países han introducido nuevos instrumentos: en Chile se estableció el impuesto específico sobre los ingresos operacionales mineros y en Bolivia se aprobó el impuesto directo sobre los hidrocarburos y sus derivados.

El segundo interrogante se relaciona con el papel que desempeña la política fiscal en la estabilización de la economía. En este sentido, con frecuencia se recomienda que durante los períodos de bonanza de la economía las autoridades fiscales debieran influir sobre el nivel de actividad mediante la restricción del gasto público y que, por el contrario, en períodos de recesión la política fiscal debiera contribuir a reanimar la economía.

Por ello suele recomendarse que en el diseño de la política fiscal se tenga en cuenta su función estabilizadora. Esta política debiera tener por objetivo disociar la evolución de los ingresos, fuertemente influenciados por el ciclo económico, de la evolución del gasto. En la región los países han buscado diversas formas de respuesta, que van desde decisiones discrecionales de política fiscal a mecanismos más institucionalizados, como reglas fiscales o fondos de estabilización.

Además, en los últimos años, coincidiendo con las variaciones al alza de los precios de los bienes minerales y energéticos y su consecuente impacto en los ingresos fiscales, los países están debatiendo distintos mecanismos que les permitan reglar la utilización de los excedentes generados.

Con estos objetivos en mente, el trabajo se ha ordenado de la siguiente manera. A continuación, se analiza la importancia de la explotación de los productos no renovables en la región (sección II). Se considera la evolución de los precios de estos bienes en los últimos años y su impacto sobre la relación de precios del intercambio de los países especializados en estos productos (sección III). Se examina el desempeño de los países considerados en función de las principales 
características de la política fiscal en la región, y se analiza la evolución de las cuentas públicas ante los aumentos de los precios en los últimos años, haciendo hincapié en su impacto y en las decisiones de política adoptadas (sección IV). Por último, en la sección V se presenta una serie de conclusiones relacionadas con la política fiscal que aplican estos países y su experiencia reciente.

\section{II}

\section{La explotación de los productos no renovables en la región}

América Latina ha sido tradicionalmente una fuente clave de productos primarios para el mundo. Ya en los primeros trabajos de la CEPAL encontramos referencias a la importancia de la región en la provisión de productos básicos. ${ }^{1}$ Como se observa en el gráfico 1 , los bienes primarios siguen representando una parte significativa de las exportaciones totales de la región.
Pese al significativo esfuerzo de diversificación de las exportaciones que han hecho los países de la región en los últimos años, en gran parte de ellos hay uno o dos bienes primarios que siguen manteniendo una importante participación en el total exportado. El cuadro 1 muestra aquellos productos primarios que representaron más de $10 \%$ de las exportaciones del respectivo país en el año 2004.

GRÁFICO 1

América Latina y el Caribe: exportaciones de productos primarios, 1986-2004

(En porcentajes de las exportaciones totales)

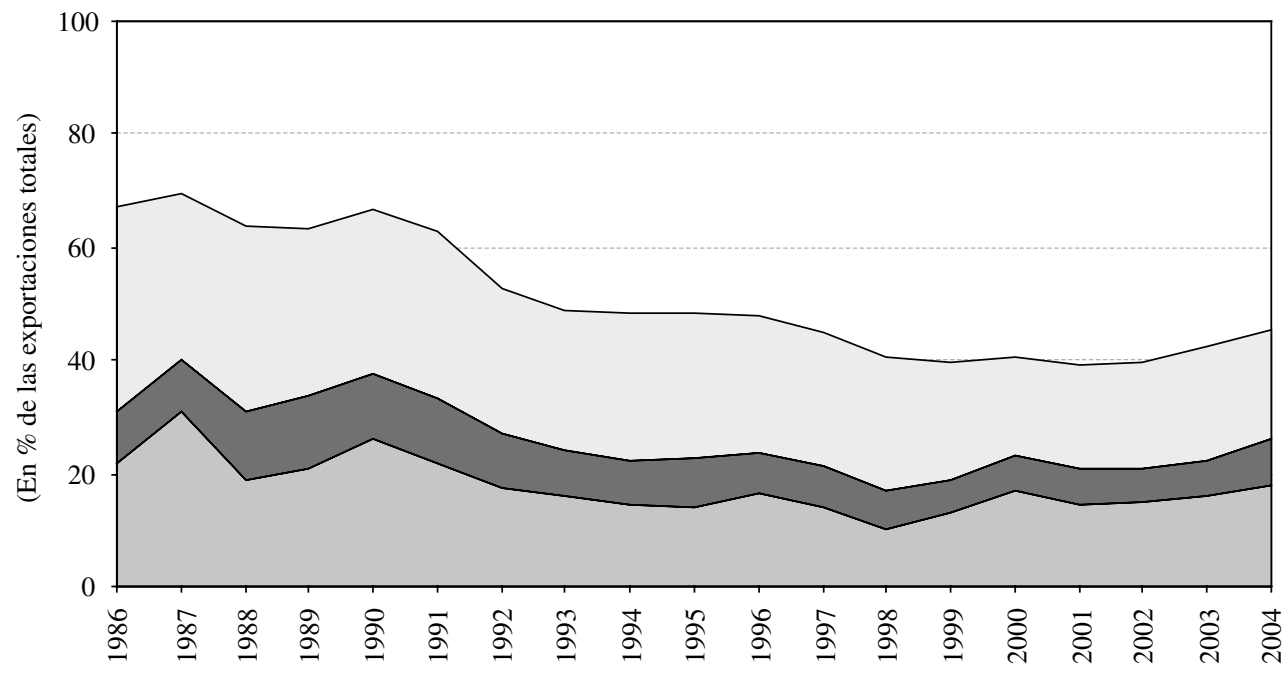

$\square$ Bienes energéticos $\square$ Bienes mineros $\quad \square$ Bienes agrícolas y alimentos

Fuente: CEPAL, con información de COMTRADE, base de datos de comercio de la División de Estadística de las Naciones Unidas.

\footnotetext{
${ }^{1}$ En El desarrollo económico de la América Latina y algunos de sus principales problemas, encontramos la siguiente cita: "En ese esquema a América Latina venía a corresponderle como parte de la pe-
}

riferia del sistema económico mundial el papel específico de producir alimentos y materias primas para los grandes centros industriales" (Prebisch, 1949). 
CUADRO 1

América Latina y el Caribe: países dependientes de la exportación de un bien primario, 2004

(Porcentajes de las exportaciones totales del país respectivo)

\begin{tabular}{lcc}
\hline Producto primario & Más de $50 \%$ & $\begin{array}{c}\text { Entre } 20 \text { y } 49 \% \\
\text { Entre } 10 \text { y } 19 \%\end{array}$ \\
de las exportaciones totales & dexportaciones totales & de las exportaciones totales \\
\hline
\end{tabular}

Bienes energéticos

Petróleo crudo y sus derivados Venezuela (Rep. Bol. de) $(81,5)$

Gas natural

Bienes minerales

Bauxita y aluminio

Carbón

Cobre

Oro

Bienes agropecuarios

Café

Plátano

Soja

Pescado

Crustáceos y moluscos

Vacuno (ganado y carne)
Ecuador $(53,2)$

Barbados (35,4), 2003

Colombia $(25,2)$

México $(38,3)^{\mathrm{a}}$

Trinidad y Tabago (38,5), 2003

Bolivia $(27,7)$,

Trinidad y Tabago (20,6), 2003

Jamaica $(65,6), 2002$

Chile $(46,1)$

Colombia $(10,6)$

Perú $(19,6)$

Perú $(18,6)$

Fuente: CEPAL, Naciones Unidas.

a Las exportaciones totales de México no incluyen las de maquila.

Entre los países especializados en la exportación de productos no renovables (lo que incluye bienes energéticos y bienes minerales, a los que en adelante denominaremos productos no renovables) sobresalen Bolivia, Chile, Colombia, Ecuador, México, Trinidad y Tabago y la República Bolivariana de Venezuela. Estos países, de acuerdo con la participación media de tales productos en sus exportaciones totales (cobre en Chile, hidrocarburos en Bolivia y Trinidad y Tabago, petróleo en los restantes países) durante el período 1980-2005, se pueden clasificar en tres grupos (gráfico 2 y cuadro 1 ):

- En el primer grupo se hallan la República Bolivariana de Venezuela y Trinidad y Tabago. Para la República Bolivariana de Venezuela, la participación anual media de las exportaciones de petróleo en sus exportaciones totales fue de $79 \%$ en el período considerado, y excepto en tres años (1981, 1982 y 1998), la cifra superó el 70\%. Para Trinidad y Tabago, la participación media anual de las exportaciones de hidrocarburos (petróleo y gas natural) en sus exportaciones totales fue de $66 \%$.

- En el segundo grupo se cuentan Chile y Ecuador, cuyas exportaciones de cobre en el primer caso y de petróleo en el segundo registraron una participación anual media superior a $40 \%$ de las exportaciones totales (40,9\% para Chile y 45,6\% para Ecuador).

- $\quad$ En el tercer grupo se encuentran Bolivia, Colombia y México, con una participación de los productos no renovables en sus exportaciones totales de entre 20 y $35 \%$. 


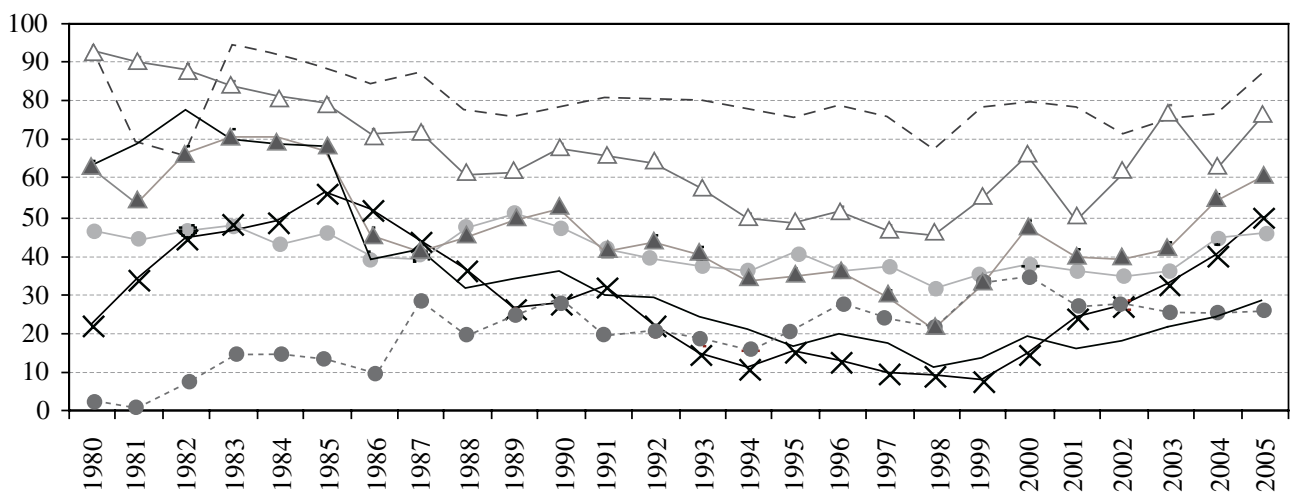

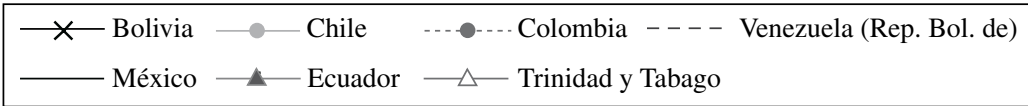

Fuente: CEPAL, sobre la base de cifras oficiales.

a Para Colombia, Ecuador, México y Venezuela (Rep. Bol. de) corresponde a las exportaciones de petróleo. En el caso de Bolivia y Trinidad y Tabago corresponde a las exportaciones de hidrocarburos (excepto en el caso de Bolivia para el período 1980-1989 donde solo corresponde a gas natural). En el caso de Chile corresponde a las exportaciones de cobre y molibdeno.

\section{III}

\section{La evolución de los precios de los productos básicos}

En los últimos años, los precios de los productos básicos que exporta América Latina y el Caribe han registrado un significativo aumento. Entre ellos, el mayor incremento lo exhibieron los productos energéticos, seguidos por los metales y minerales.

Según CEPAL (2006), y como lo ilustra el gráfico 3, tanto el índice total de productos básicos como el de los productos energéticos y minerales están en la fase expansiva del ciclo y sus precios son superiores a las tendencias de las series. En ese sentido, el ciclo actual se diferencia de anteriores por la magnitud y duración de la fase de recuperación.

En la serie del índice de precios de los productos energéticos (constituido en un $70 \%$ por el petróleo crudo) se observan fuertes aumentos en los últimos dos años (2004-2005). El incremento del precio del petróleo se ha debido fundamentalmente a la expansión de la demanda de crudo (impulsada por China e India); en el caso de los metales, el alza de los precios se ha debido a la expansión de la demanda externa, combinada con bajos inventarios. $^{2}$

En lo que se refiere al petróleo, en los últimos años su precio registró importantes fluctuaciones (gráfico 4). Luego de un período de grandes alzas en la década de 1970 y la primera mitad de la década de 1980, los precios se mantuvieron relativamente estables (con un salto en 1990-1991, durante el conflicto en Medio Oriente) hasta 1997. A partir de ese año la volatilidad se acentuó notablemente, observándose significativos aumentos en los últimos años.

\footnotetext{
${ }^{2}$ Véanse más detalles en CEPAL (2006) y Ovalle (2006)
} 
GRÁFICO 3

América Latina y el Caribe: índice de precios, series, tendencias y componentes cíclicos, 1970-2005 $(2000=100)$

Índice de precios productos básicos Serie y tendencia

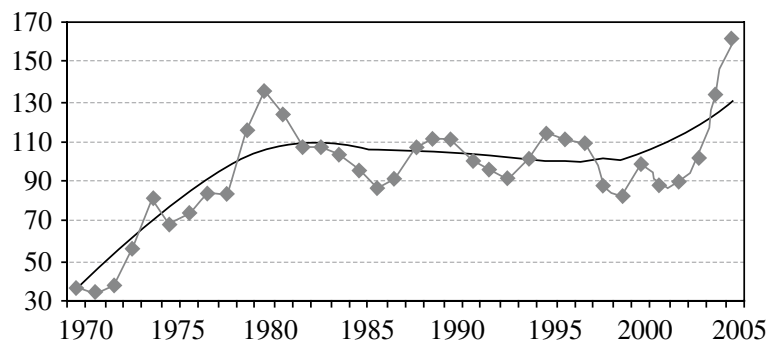

Índice de precios productos energéticos Serie y tendencia

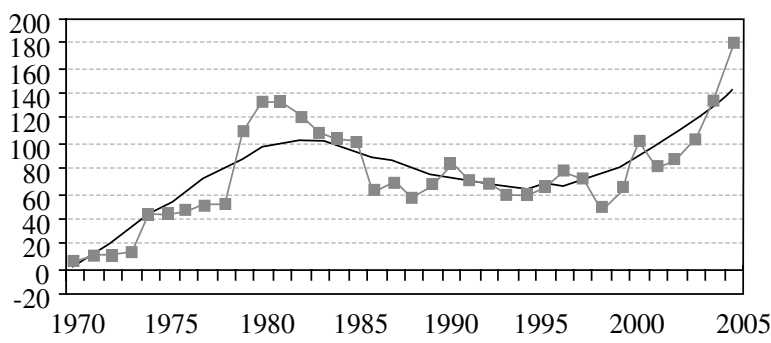

Índice de precios minerales y metales Serie y tendencia

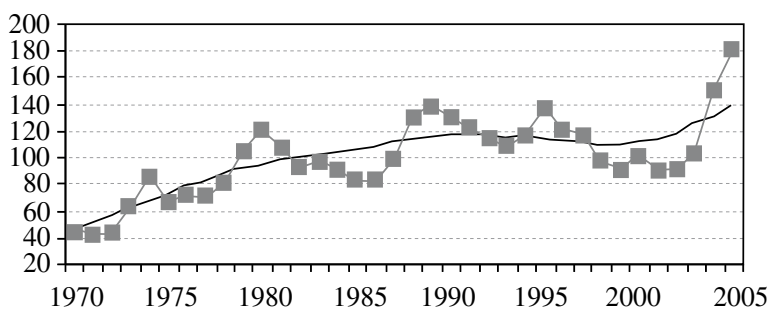

Fuente: CEPAL, sobre la base de cifras oficiales.

El precio del cobre también ha mostrado una gran variabilidad en los últimos 25 años, aunque menor que la del precio del petróleo. ${ }^{3}$ Puesto que Chile es el primer productor y exportador de cobre a escala mundial (genera en promedio 35\% de la producción mundial del cobre de mina), su política minera tiene una influencia directa sobre el precio de este producto en el mercado internacional. Durante la década de 1990 la producción

\footnotetext{
${ }^{3}$ En Jiménez y Tromben (2006) se muestra que para el período 1957-2005 el coeficiente de variación del cobre es menor que para el petróleo y el gas.
}

Índice de precios de productos básicos Componente cíclico

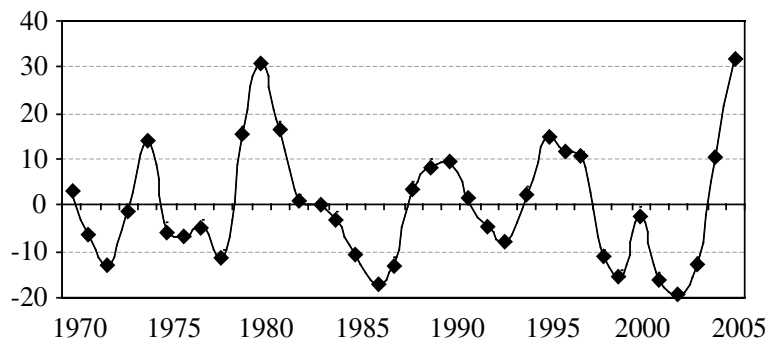

Índice de precios productos energéticos Componente cíclico

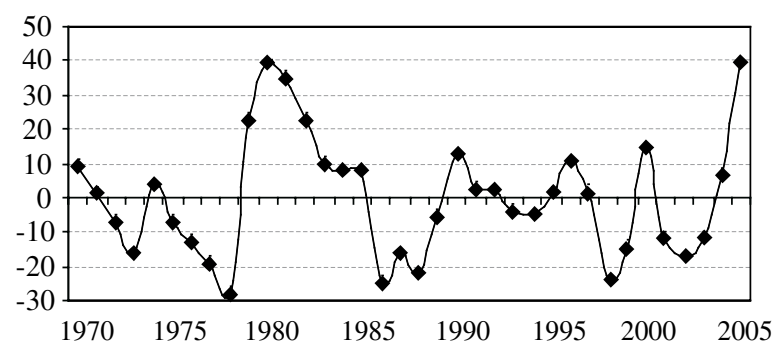

Índice de precios minerales y metales Componente cíclico

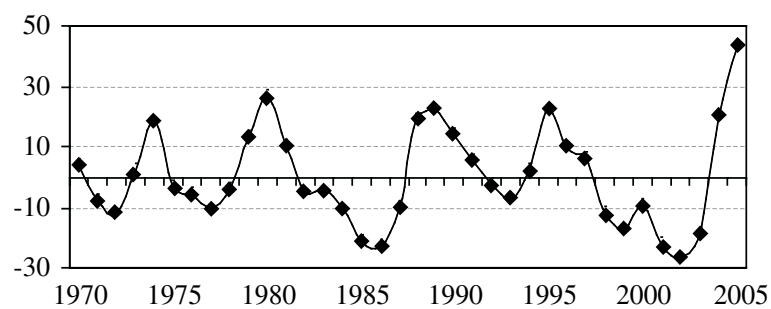

de cobre y la inversión cuprífera en Chile se incrementaron fuertemente y la sobreproducción consecuente habría inducido una significativa baja en el precio del mercado internacional. Desde 2002, el precio del cobre, como el del petróleo, retoma el ciclo expansivo debido fundamentalmente a la creciente demanda por parte de las grandes economías asiáticas. ${ }^{4}$

\footnotetext{
${ }^{4}$ Para más detalle en relación con la entrada de la República Popular China en el mercado global y su impacto en la demanda de bienes primarios, véase Kaplinsky (2005). De acuerdo con este autor, se identifican tres tendencias que tienen un significativo impacto sobre la evolución de los términos de intercambio de la región: i) no es
} 

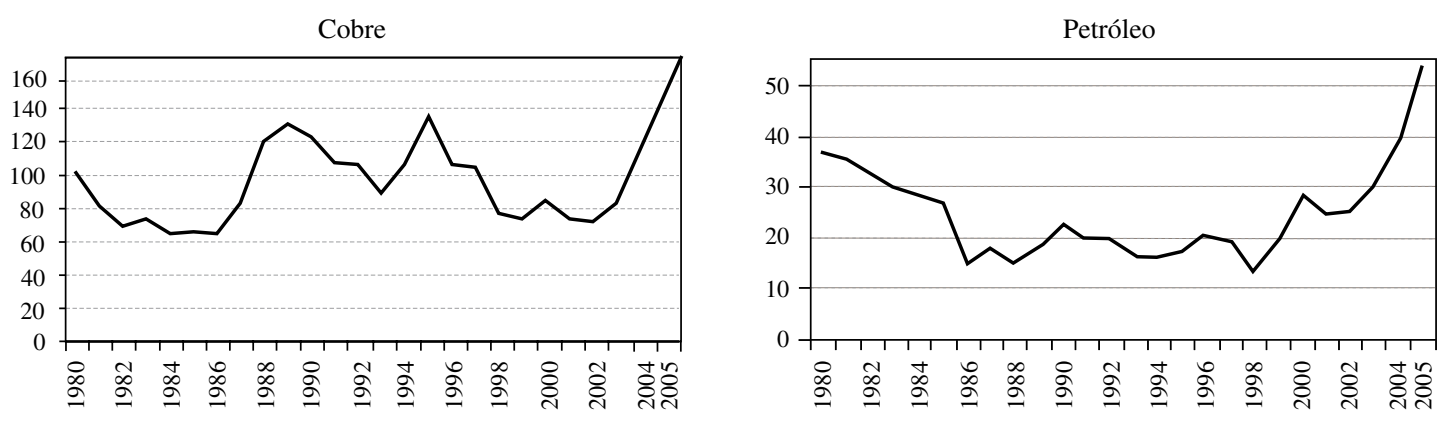

Gas natural

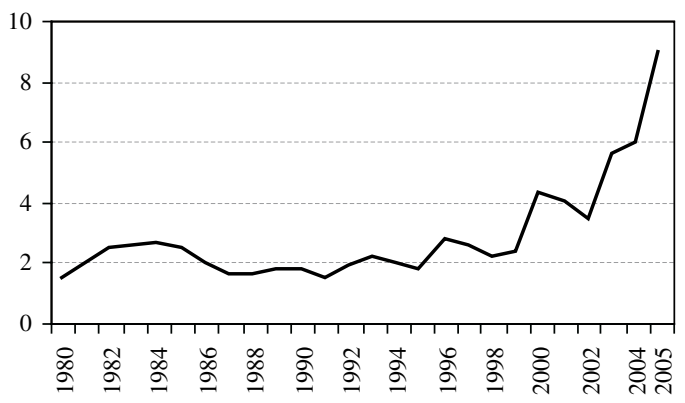

Fuente: Banco Mundial.

El significativo incremento en los precios de los productos en los que se especializa la región permitió una fuerte mejora en la relación de precios del intercambio. La alta participación relativa de los productos básicos en el total de exportaciones se traduce en que los términos de intercambio de la región guardan una relacion estrecha con el índice de precios de los productos básicos de exportación. De acuerdo con CEPAL (2006), existe una correlación estadísticamente significativa entre estas dos variables, de 0,65 desde principios de la década de 1990. No obstante, como se observa en el gráfico 5 , este proceso muestra importantes diferencias entre países.

Los países que registraron una mejora más pronunciada en los términos de intercambio en el período 2003-2005 son la República Bolivariana de Venezuela, Ecuador, Chile y Colombia. En el caso de la República Bolivariana de Venezuela, Ecuador y Colombia esta

inevitable que los precios de los "bienes primarios blandos" caigan; ii) aparecen dudas sobre si efectivamente los precios de los productos manufacturados seguirán aumentando, sobre todo, aquellos en que China participa; iii) el precio de muchos de los "bienes primarios duros", que registraban una importante declinación en el largo plazo, están creciendo desde comienzos de la década del 2000. mejora es reflejo del alto precio del petróleo. En el caso de Chile, país importador de petróleo, ella se debe a que el alza del precio del cobre compensó con creces el aumento del precio del crudo.

En los últimos años, la creciente participación de las grandes economías asiáticas en el comercio internacional ha tendido, por una parte, a cambiar la estructura de la demanda global a favor de las materias primas y de ciertas manufacturas y, al mismo tiempo, ha provocado un considerable aumento de la oferta de un gran número de productos manufacturados. Como resultado, los términos de intercambio de América Latina se han recuperado de la caída del decenio de 1980 y su evolución muestra una tendencia volátil, pero positiva, desde la década de $1960 .{ }^{5}$ Esta nueva estructura de la oferta y la demanda mundial de bienes podría dar lugar a cambios de largo plazo en la tendencia de los precios de los productos primarios y los productos básicos manufacturados, lo que debe tenerse especialmente en cuenta al diseñar los instrumentos fiscales.

\footnotetext{
${ }^{5}$ Véase CEPAL (2005a y 2005b).
} 


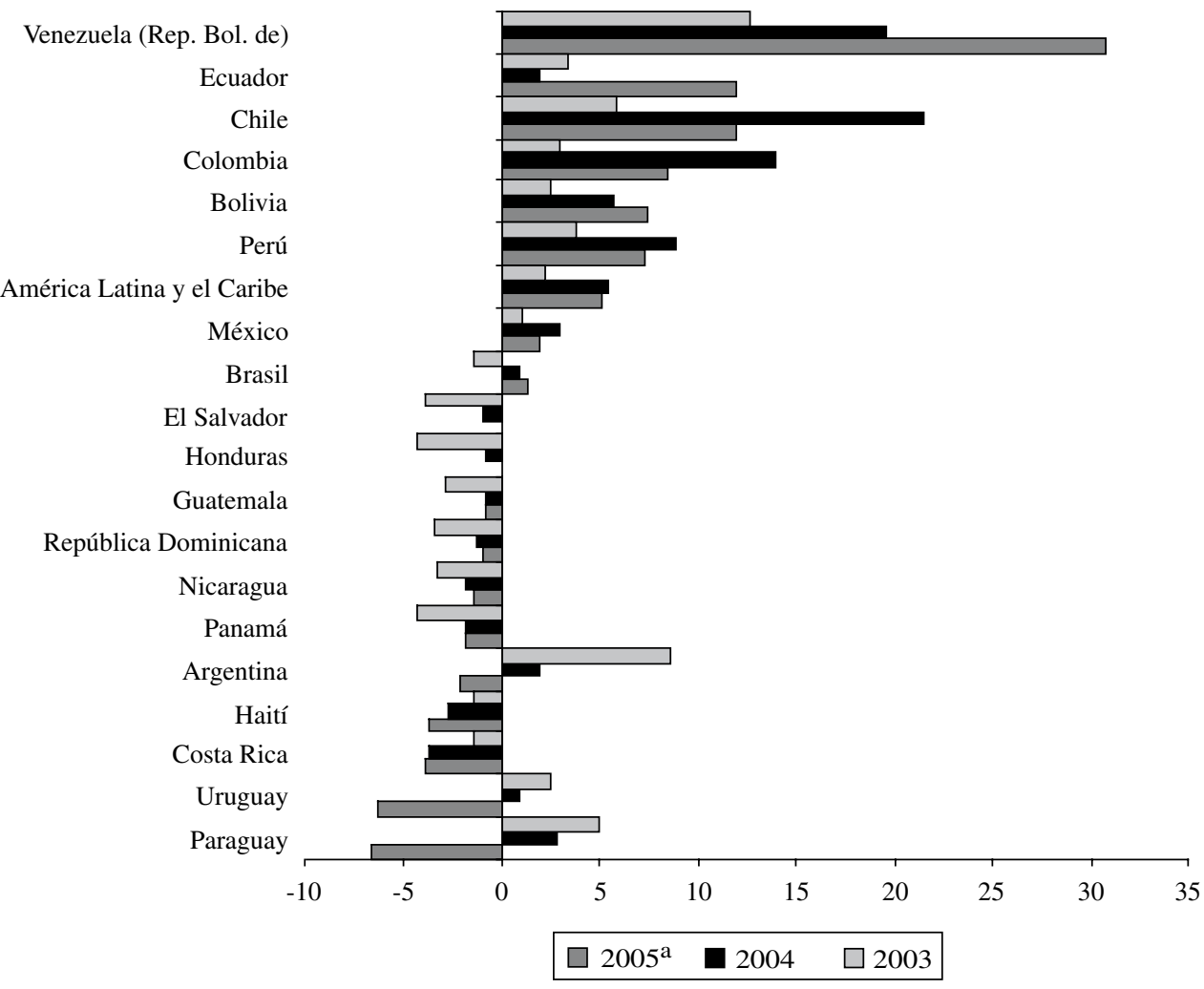

Fuente: CEPAL, sobre la base de cifras oficiales.

a Cifras preliminares.

\section{IV}

\section{La política fiscal en países exportadores de productos no renovables}

Con el objeto de examinar la política fiscal que han llevado adelante los países bajo análisis, se dividirá esta sección en dos apartados. En primer lugar, se analizará cuál ha sido el comportamiento de estos países en relación con las características más salientes de la política fiscal en América Latina. En segundo lugar, se examinará, particularmente en estos países, el desempeño que han tenido ante el auge de precios de los últimos años, haciendo hincapié en dos de los aspectos principales que debe enfrentar su política fiscal: cómo los gobiernos logran captar los recursos provenientes de los productos no renovables y, sobre todo, el impacto en los ingresos fiscales del aumento de los precios de los productos, para luego analizar de qué manera han manejado esta abundancia para atenuar su impacto sobre el gasto.

A los desafíos que habitualmente enfrenta la política fiscal en países cuya estructura productiva se concentra en productos no renovables, se les deben sumar los que 
derivan de las características intrínsecas de estos productos. Lo imprevisible y volátil de sus precios puede complicar la política fiscal, dificultando la tarea de determinar el nivel apropiado y sostenible de gasto público. ${ }^{6}$ Además, puesto que los yacimientos son agotables, al diseñar las políticas fiscales es preciso incorporar consideraciones de equidad entre diferentes generaciones. ${ }^{7}$

\section{Solvencia, volatilidad y ciclo}

Tres características deben resaltarse cuando se procura describir la política fiscal en países de América Latina y el Caribe: los problemas de solvencia, la volatilidad y el comportamiento procíclico. Los problemas de solvencia se relacionan con la dificultad que tienen los gobiernos de la región para financiar en forma sostenible la provisión de los bienes y servicios que ofrecen sus sectores públicos. Para ilustrar lo dicho, debe tenerse en cuenta que de los 304 resultados que se observaron desde 1990 a 2005 en los 19 países que componen la base de datos de la CEPAL, solo en 48 oportunidades los resultados fiscales fueron positivos. Si se les desagrega por décadas, se ve que en el período 1990-1994 hubo 29 resultados fiscales positivos, solo nueve entre 1995 y 1999 y finalmente 10 entre 2002 y 2005 (durante los años 2000 y 2001 no se observó resultado fiscal positivo alguno). Ampliando la cobertura temporal al período 1950-2005 (gráfico 6), de 976 observaciones sólo 181 corresponden a superávit fiscales, lo que representa menos del $20 \%$ del total.

$\mathrm{Si}$ se desagregan los resultados entre aquellos correspondientes a países especializados en productos no renovables y aquellos del resto de los países de la región, se observa que los primeros han tenido resultados fiscales menos deficitarios que los segundos. En el período 1950-2005 los países especializados en productos no renovables registraron un déficit medio de $1,74 \%$ del producto nterno bruto (PIB) mientras que el resto tuvo un promedio de $2,75 \%$ del PIB. Como se observa en el gráfico 7, los años de auge del precio del petróleo explican en gran parte la diferencia en los resultados fiscales de uno y otro grupo.

GRÁFICO 6

América Latina y el Caribe: ingresos y gastos fiscales, 1950-2005

(En porcentajes del producto interno bruto)

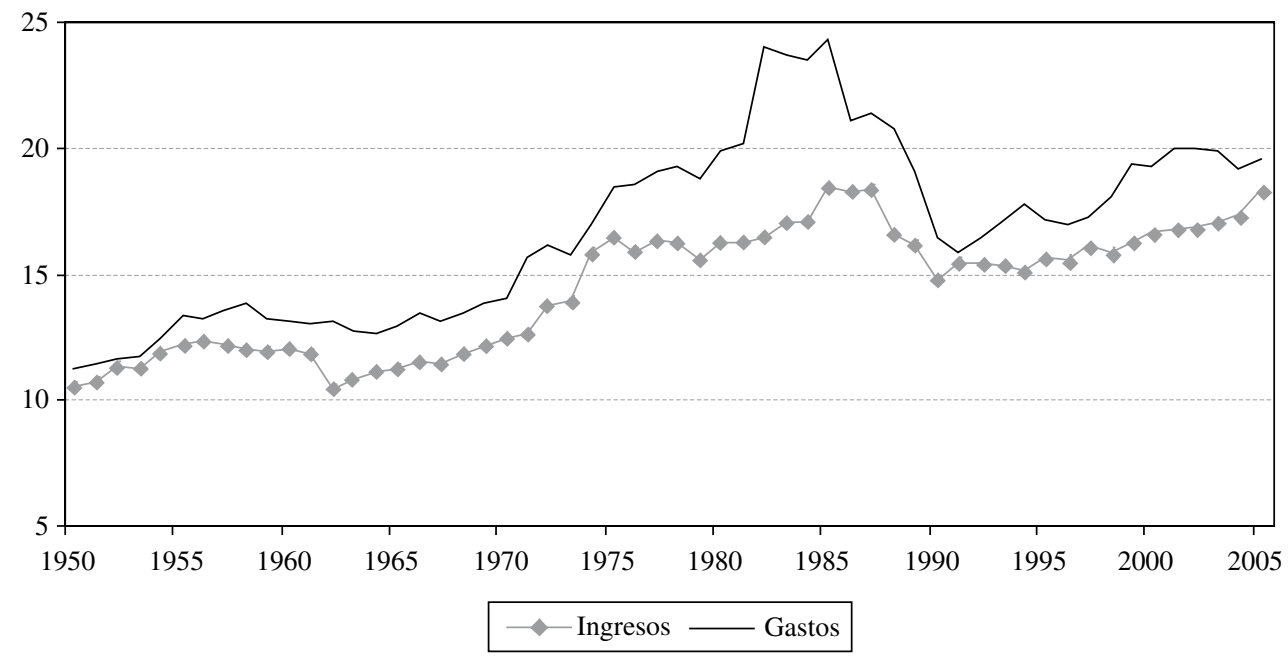

Fuente: elaboración propia sobre la base de datos de OXLAD e ILPES. Se presenta el promedio simple. Cubre el gobierno central.

\footnotetext{
${ }^{6}$ Rigobón (2006) enumera las respuestas típicas de la política fiscal a la volatilidad e incertidumbre de los ingresos fiscales: i) privatización de la fuente de la volatilidad; ii) uso de los mercados financieros como medio para transferir el riesgo, y iii) autoseguro, fundamentalmente a través de la implementación de fondos contingentes.

${ }^{7}$ Véanse más detalles, sobre las particularidades de la política fiscal de este tipo de países en Jiménez y Tromben (2006).
}

\footnotetext{
${ }^{8}$ Esta serie se confeccionó utilizando la base de datos Oxford Latin American Economic History Database (OXLAD), de la Universidad de Oxford, para el período 1950-1989; y la base de datos de la CEPAL, desarrollada por el Instituto Latinoamericano y del Caribe de Planificación Económica y Social (ILPES) para el período 1990-2005.
} 


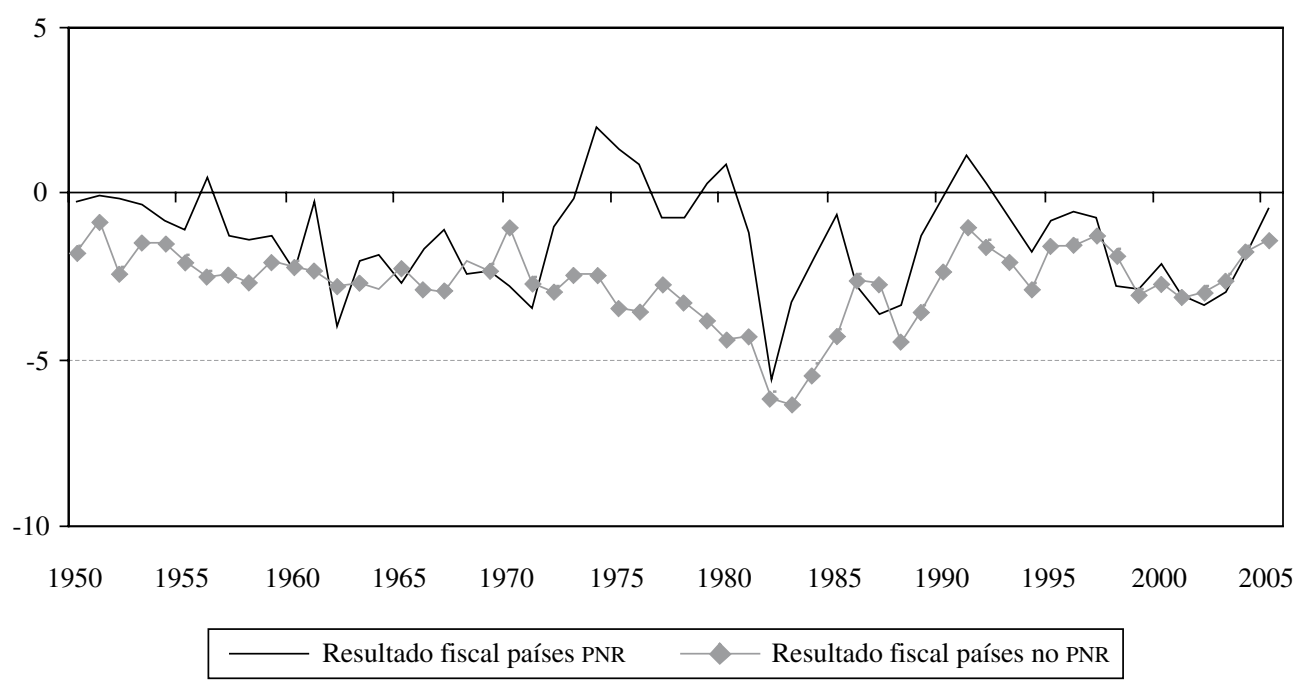

Fuente: elaboración propia sobre la base de datos de OXLAD e ILPES. Se presenta el promedio simple. Cubre el gobierno central.

Otra característica destacada de la política fiscal de los países de la región ha sido su significativa volatilidad. Los resultados fiscales de América Latina y el Caribe han sido mucho más fluctuantes que los observados en los países de la Organización de Cooperación y Desarrollo Económicos (OCDE), ya sea medidos como porcentaje del PIB, como participación de los recursos fiscales totales o en relación con el tamaño del sistema financiero interno (Gavin, Hausmann y otros, 1996; Alesina y Tabellini, 2005). Esta alta volatilidad se observa tanto en los resultados como en los ingresos y los gastos (Jiménez y Tromben, 2006).

Los ingresos fiscales de los países especializados en productos no renovables pueden desagregarse entre aquellos provenientes de la explotación de los productos no renovables y aquellos originados en otras fuentes. Como se observa en el cuadro 2, los ingresos generados por los productos no renovables fluctúan mucho más que los ingresos totales. En el caso de la República Bolivariana de Venezuela, la alta volatilidad de los ingresos fiscales totales se origina tanto en los ingresos provenientes del petróleo como en el resto de los ingresos. En el caso de Chile, con recursos provenientes del cobre altamente volátiles, la mayor estabilidad del resto de los ingresos (junto con la menor participación de los recursos provenientes de productos no renovables sobre el total) hace que los ingresos totales acusen una fluctuación menor que el promedio de la región.

La alta volatilidad de estas bases imponibles se neutraliza a medida que sea mayor el nivel de diversificación de las estructuras de ingresos fiscales. La variabilidad de los ingresos se encuentra en gran parte determinada por la participación que tienen los recursos provenientes de los productos no renovables en el total.

No sólo los recursos tributarios se han comportado de manera volátil en la región. En el gasto primario (que excluye los intereses de la deuda) y durante el período 1990-2004, se observa en promedio una mayor volatilidad que en los recursos (Jiménez y Tromben, 2006). Esto no deja de ser llamativo, pues se esperaría, como sucede en los países de la OCDE, que los ingresos fuesen más volátiles que el gasto (Gavin, Hausmann y otros, 1996). ${ }^{9}$

Esta llamativa volatilidad se asocia con la tercera característica de la política fiscal de la región: su relación

\footnotetext{
${ }^{9}$ Esta volatilidad podría ser justificada en el caso de que resulte de movimientos contracíclicos que compensen y estabilicen los choques macroeconómicos que impactan sobre los ingresos fiscales. No obstante, la evidencia empírica sugiere lo contrario: el gasto primario en la región ha sido procíclico, amplificando más que absorbiendo los choques exógenos (Alesina y Tabellini, 2005).
} 
Países latinoamericanos especializados en productos no renovables: coeficiente de variación de los ingresos fiscales, 1990-2005 (En porcentajes)

\begin{tabular}{|c|c|c|c|c|}
\hline & \multicolumn{3}{|c|}{ Coeficiente devariación (\%) } & \multirow{2}{*}{$\begin{array}{c}\text { Participación de los ingresos } \\
\text { provenientes de productos } \\
\text { no renovables/ingresos fiscales } \\
\text { totales }(\%)\end{array}$} \\
\hline & $\begin{array}{c}\text { Ingresos } \\
\text { totales }\end{array}$ & $\begin{array}{l}\text { Ingresos provenientes } \\
\text { de productos } \\
\text { no renovables }\end{array}$ & $\begin{array}{c}\text { Otros } \\
\text { ingresos }\end{array}$ & \\
\hline Bolivia & 10,6 & 24,7 & 16,9 & 25,3 \\
\hline Chile & 5,9 & 77,2 & 4,4 & 7,4 \\
\hline Colombia & 16,9 & 38,3 & 15,7 & 11,3 \\
\hline Ecuador & 10,7 & 26,4 & 11,3 & 30,0 \\
\hline México & 7,5 & 12,5 & 11,5 & 30,9 \\
\hline Venezuela (Rep. Bol. de) & 16,6 & 33,2 & 35,0 & 55,2 \\
\hline Promedio países PNR & 11,4 & 35,4 & 15,8 & 26,7 \\
\hline Promedio países no PNR & 9,2 & & & \\
\hline
\end{tabular}

Fuente: cálculos propios sobre la base de datos de la CEPAL.

con el ciclo económico. Varios trabajos han documentado que la política fiscal de América Latina y el Caribe ha tenido un comportamiento que puede caracterizarse como procíclico, ${ }^{10}$ particularmente porque el gasto público se ha incrementado en períodos de auge y ha caído en los de recesión, mientras que en los países de la OCDE las cuentas públicas han mostrado un comportamiento inverso.

Hay diferentes formas de evaluar la relación entre la política fiscal y el ciclo. En este caso, y con la intención de probar cuál ha sido el comportamiento de los países bajo análisis comparados con el resto de la región, se procederá de dos maneras.

En primer lugar, siguiendo la metodología definida en Martner y Tromben (2003), se efectuará un análisis gráfico para detectar los episodios del ciclo del PIB en cada país y observar la posición fiscal resultante de 18 países de la región en el período 1980-2005. Para ello se necesitan dos variables: la brecha de $\operatorname{PIB}^{11} \mathrm{y}$

\footnotetext{
${ }^{10}$ Gavin y Perotti (1997) han señalado que la política fiscal en América Latina es procíclica, mientras que Talvi y Vegh (2000), Catão y Sutton (2002), Kaminsky, Reinhart y Vegh (2004) y Alesina y Tabellini (2005) notaron que este no es un fenómeno exclusivo de América Latina: una política fiscal procíclica es un comportamiento común a muchos países en desarrollo. En Martner y Tromben (2003) el análisis de 45 episodios fiscales (donde se observan los cambios en el saldo global cíclicamente ajustado) entre 1990 y 2001 revela que en 25 de ellos la política fiscal ha mostrado un comportamiento procíclico, mientras que en sólo ocho casos se registró un comportamiento contracíclico.

${ }^{11}$ La brecha de PIB se calcula con el filtro Hodrick-Prescott. Aquí se analizan los ciclos y no los años puntuales, por lo que un ciclo negativo se define como el período en el cual el PIB efectivo es inferior al PIB
}

el cambio en el saldo cíclicamente ajustado. ${ }^{12}$ En el gráfico 8 cada punto representa un ciclo económico con su correspondiente posición fiscal. Más específicamente, lo que se observa es el promedio de la brecha de PIB durante un ciclo económico en un país determinado en el eje horizontal, y el promedio del cambio en el saldo cíclicamente ajustado durante ese mismo período en el eje vertical. La lectura del gráfico indicado es la siguiente: el cuadrante superior izquierdo y el inferior derecho indican posiciones fiscales procíclicas; los otros dos cuadrantes indican posiciones fiscales contracíclicas, mientras que los puntos cercanos al eje horizontal indican episodios fiscales neutros al ciclo económico. Se observa que la gran mayoría de los ciclos y episodios fiscales se encuentra en los dos cuadrantes correspondientes a posiciones procíclicas (66\% del total). Los países que han tenido más de un episodio contracíclico $(12 \%)$ o neutro (22\%) han sido Chile, Guatemala, México y Panamá.

de tendencia (es decir, la brecha de PIB es negativa). Por otro lado, un ciclo positivo se define como el período en el cual el PIB efectivo es superior al PIB de tendencia (es decir, la brecha de PIB es positiva).

${ }^{12}$ El cambio en el saldo cíclicamente ajustado $\left(\mathrm{S}^{\mathrm{CA}}\right)$ se calcula: $\Delta S^{C A}=S^{C A_{t}}-S^{C A_{t-1}}$,

donde $\mathrm{S}^{\mathrm{CA}}-\mathrm{S}^{\text {Efectivo }}-\mathrm{S}^{\text {Cíclico }}$

$\mathrm{S}^{\text {Cíclico }}=($ Ingresos Tributarios * Brecha PIB $)$,

lo que supone una elasticidad de los ingresos tributarios igual a la unidad, junto con la no incorporación de ingresos no tributarios y del gasto público en el saldo cíclico. 


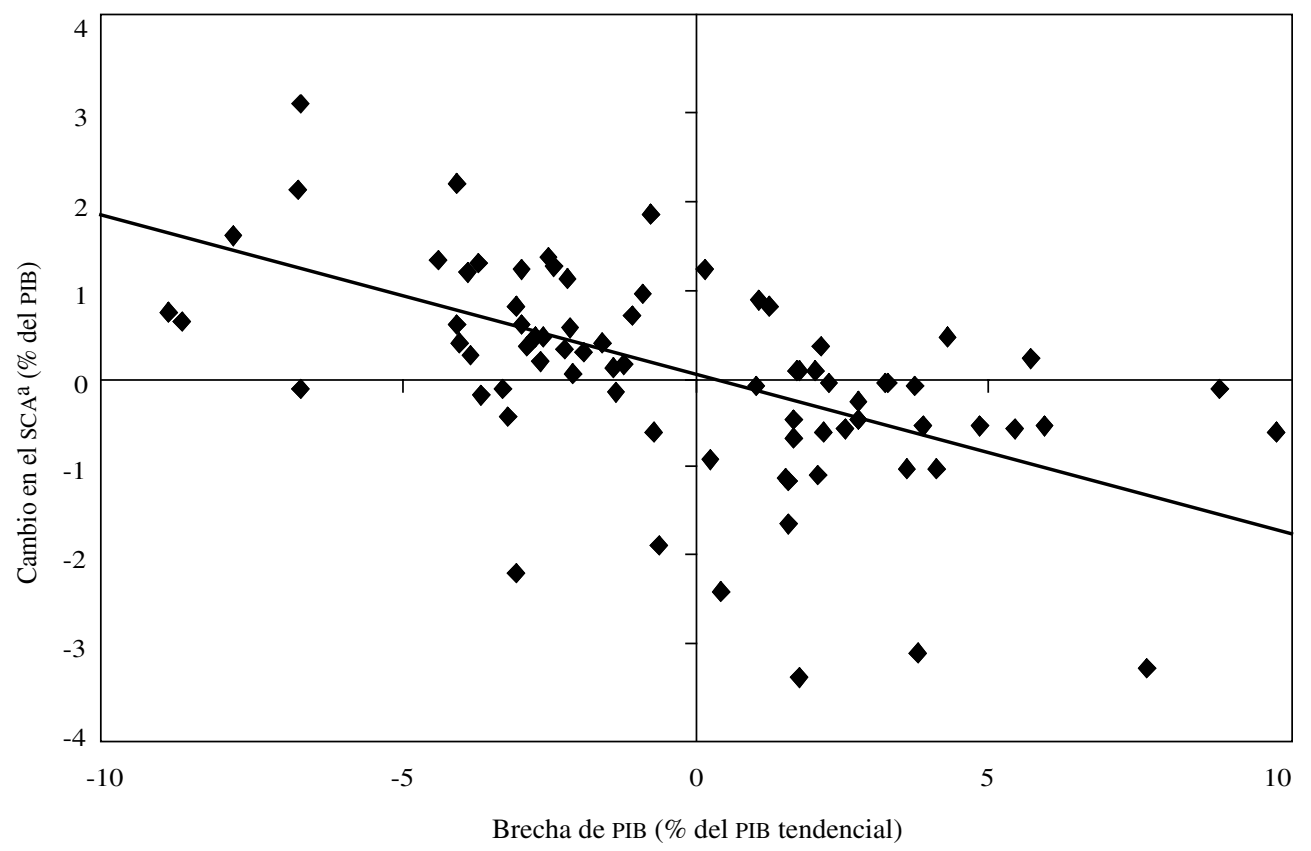

Fuente: elaboración propia.

a Saldo cíclicamente ajustado.

En el gráfico 9 se utilizará la misma metodología, diferenciando los países, según su especialización o no especialización, en productos no renovables para un período más reciente (1990-2005). Los recuadros superiores ilustran el cambio en el saldo cíclicamente ajustado, mientras que los inferiores muestran los cambios en el saldo primario cíclicamente ajustado. De acuerdo con este primer análisis, los países dependientes de productos no renovables exhiben un comportamiento también mayoritariamente procíclico ( $47 \%$ del total), pero con un número mayor de casos neutros $(35 \%$ del total) que los demás países de la región.

La segunda manera de evaluar la relación entre la política fiscal y el ciclo económico es a través de estimaciones econométricas. Para ello, y como no se dispone de series históricas homogéneas, se efectuará una estimación para tres paneles de datos distintos: primero, América Latina y el Caribe en su conjunto; segundo, los países especializados en productos no renovables (PNR), y tercero, el resto de los países (no PNR).
La especificación de la regresión es la siguiente: $\Delta\left(\right.$ saldo $\left._{i t}\right) \alpha+\beta$ brechaPIB $_{i t}+\delta\left(\right.$ saldo $\left._{i t-1}\right)+\gamma T D I_{i t}+\epsilon_{i t}$

La especificación de $\beta$ se corresponde con la medida de relación entre ciclo y política fiscal calculada por Alesina y Tabellini (2005). Las tres variables explicativas son: la brecha de PIB (la diferencia en términos logarítmicos entre el PIB y su valor de tendencia medido con el filtro Hodrick-Prescott), un rezago del saldo fiscal, y la relación de precios del intercambio (medida como la brecha existente con su valor de tendencia usando el filtro Hodrick-Prescott). Un coeficiente $\beta$ negativo indica que un choque positivo en la economía (es decir, una brecha de PIB positiva) se asocia con un deterioro del saldo fiscal, por lo que la política fiscal es procíclica. Lo contrario ocurre con un coeficiente $\beta$ positivo. En el cuadro 3 se muestran los resultados de las estimaciones.

Con esta especificación se encuentran signos negativos para los tres paneles de datos, lo que nuevamente indica un comportamiento fiscal procíclico en los países de la región, sean estos dependientes o no dependientes de la explotación de productos no renovables. 
GRÁFICO 9

\section{América Latina y el Caribe: ciclo económico y posición fiscal por grupos de países, ${ }^{a}$ 1990-2005 (En porcentaje del producto interno bruto)}

Países no PNR
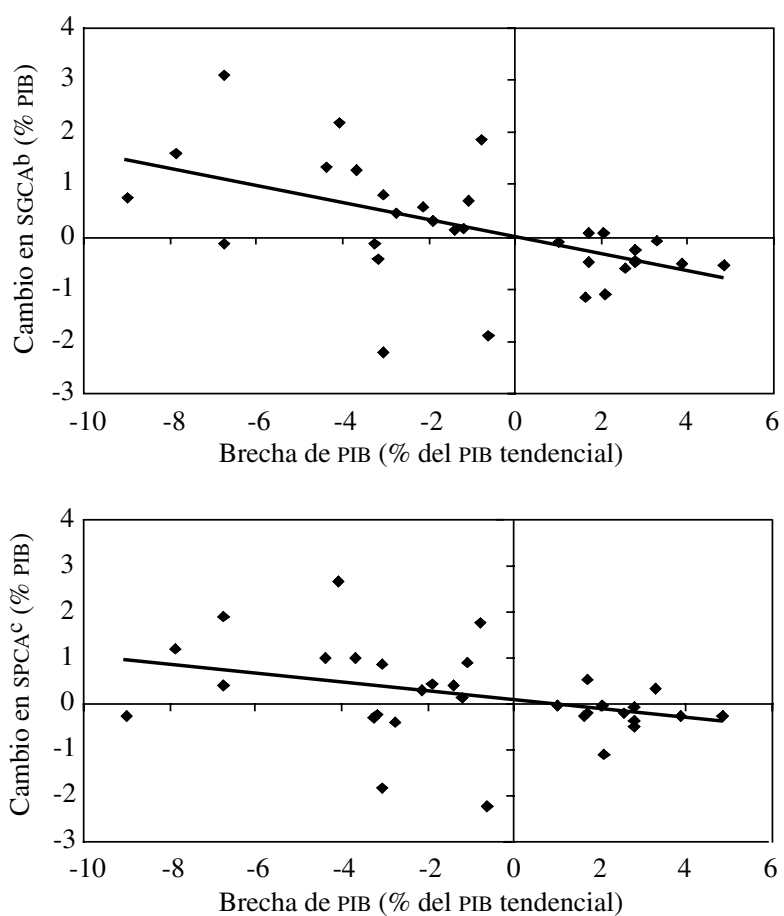

Países PNR
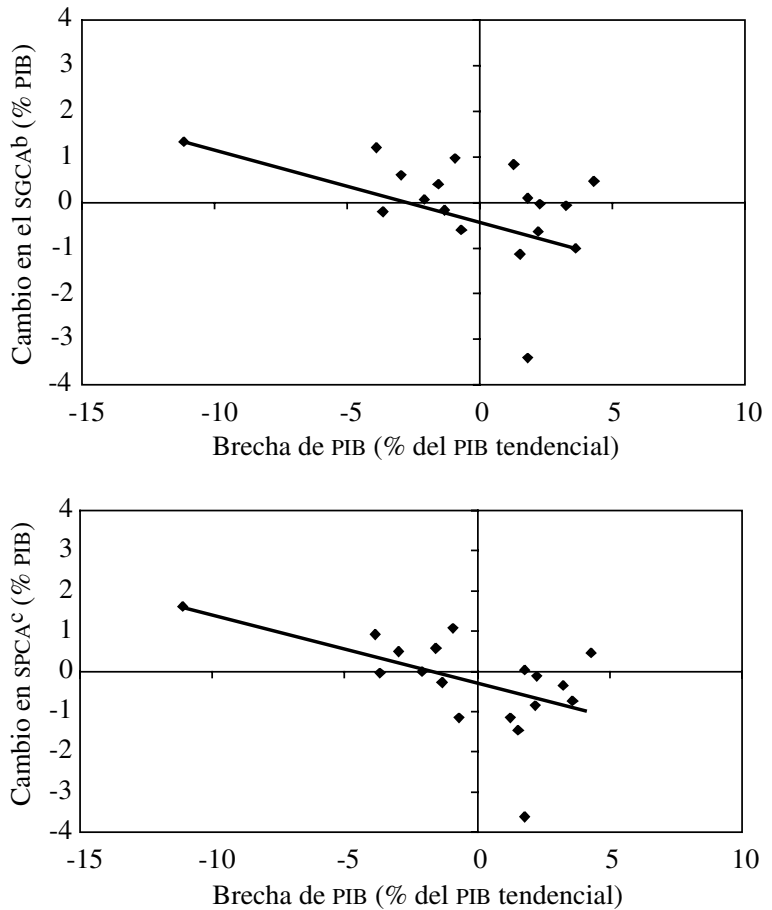

Fuente: elaboración propia.

a Países no especializados en productos no renovables (no PNR) y países especializados en productos no renovables (PNr).

b $S G C A=$ saldo global cíclicamente ajustado.

c $S P C A=$ saldo primario cíclicamente ajustado.

CUADRO 3

América Latina: política fiscal y ciclo económico, por grupos de países

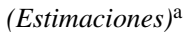

América Latina

Países especializados

en productos no renovables
Países no especializados en productos no renovables
Brecha de PIB

S (-1)

Relación de precios del intercambio

$\mathrm{N}^{\mathrm{o}}$ Observaciones

$\mathrm{R}^{2}$

Fuente: elaboración propia.

a Estimaciones de panel de datos con efectos fijos por país. Los valores entre paréntesis son estadísticos $t$. La muestra corresponde al período 1980-2005.

b Denota significación al $5 \%$.

c Denota significación al $10 \%$

d Denota significación al $1 \%$. 


\section{La política fiscal y los precios de los productos}

A las particularidades que las autoridades fiscales de estos países deben enfrentar, dada su especialización en productos volátiles y agotables, debe sumársele en los últimos años el debate sobre la política fiscal en momentos de abundancia, producto del aumento de los precios de estos bienes. Entre las numerosas interrogantes que esta situación plantea, dos parecen ser las principales que encaran los responsables de la política fiscal de estos países: en primer lugar, cuál es la mejor manera de transformar en recursos fiscales los ingresos provenientes de la bonanza de los precios; y en segundo lugar, cuál debiera ser el comportamento o mecanismo adecuado para utilizar estos excedentes fiscales sin suscitar los problemas macroeconómicos que suelen observarse en estos períodos de auge.

La primera pregunta tiene que ver con la manera en que los gobiernos logran captar los recursos provenientes de la explotación de los recursos no renovables. Como se dijo antes (gráfico 9), la evolución y la dimensión relativa de esos recursos no son homogéneas en la región. Mientras que en Chile, los recursos fiscales medios generados anualmente por la explotación del cobre en el período 1990-2005 no llegaron al 10\% de los ingresos totales, en Colombia los originados en el petróleo representaron alrededor del $11 \%$, en Bolivia el $25 \%$, en Trinidad y Tabago el $30 \%$, en Ecuador y México cerca del $40 \%$ y en la República Bolivariana de Venezuela más del $50 \%$.

La diferente composición de la estructura de ingresos de estos países se debe a los diversos instrumentos utilizados para gravar los sectores mencionados y al peso relativo de los productos no renovables. La importancia estratégica de dichos sectores en estas economías, unida al incremento de los precios en los últimos años, los ha transformado en uno de los objetivos centrales de las políticas tributarias de los respectivos gobiernos, que al respecto han diseñado diversos mecanismos de recaudación de recursos.

Por supuesto que estas herramientas van a ser diferentes, dependiendo de si la propiedad de estos recursos es pública o privada. La forma más directa de transformar los ingresos procedentes de la explotación de estos productos en recursos fiscales ha sido la participación directa de los gobiernos en la producción a través de empresas de propiedad pública.

En la medida en que una proporción importante de la explotación de estos recursos está en manos del sector privado, los países han diseñado distintos mecanismos e impuestos específicos para apropiarse de una parte de los

GRÁFICO 10

América Latina y el Caribe (siete países): participación de los ingresos fiscales provenientes de productos no renovables en el total de ingresos fiscales de cada país (En porcentajes del total de los ingresos fiscales)

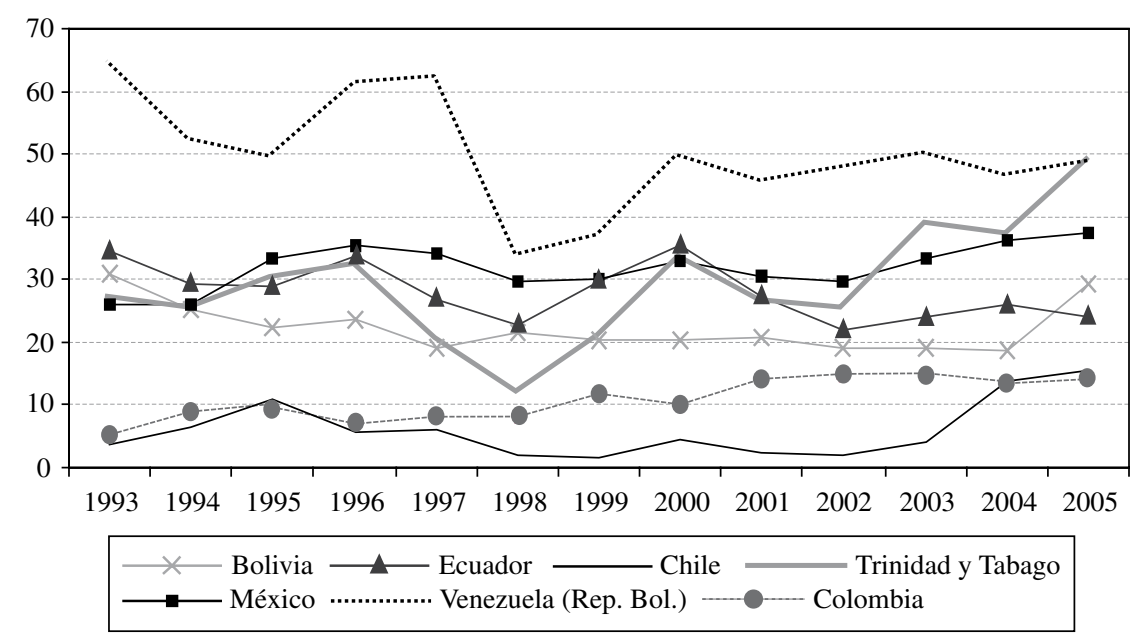

Fuente: CEPAL, sobre la base de cifras oficiales. Para Bolivia la cobertura corresponde al gobierno general; para Chile, Colombia y Venezuela corresponde al gobierno central; para los demás países, corresponde al sector público no financiero. 
CUADRO 4

\section{América Latina (siete países): características de los regímenes tributarios aplicados a los productos no renovables}

\begin{tabular}{|c|c|c|c|c|c|}
\hline País y producto & $\begin{array}{l}\text { Regalías } \\
\text { (alícuotas) }\end{array}$ & $\begin{array}{l}\text { Impuesto sobre los } \\
\text { ingresos (alícuotas) }\end{array}$ & $\begin{array}{c}\text { Impuesto sobre } \\
\text { las utilidades (alícuotas) }\end{array}$ & Otros tributos & $\begin{array}{l}\text { Participación } \\
\text { pública }\end{array}$ \\
\hline $\begin{array}{l}\text { Bolivia } \\
\text { (hidrocarburos) }\end{array}$ & $\begin{array}{l}\text { Regalías nacionales: } 6 \% \\
\text { Regalías departamenta- } \\
\text { les: } 12 \% \\
\text { Participaciones del Tesoro } \\
\text { General de la Nación: } 6 \%\end{array}$ & $\begin{array}{l}\text { Impuesto Directo a } \\
\text { los Hidrocarburos } \\
\text { (IDH): } 32 \% \text { sobre } \\
\text { la producción de } \\
\text { hidrocarburos }\end{array}$ & $\begin{array}{l}\text { Impuesto sobre las Uti- } \\
\text { lidades de las Empresas } \\
\text { (IUE): } 25 \% \text { y } 12,5 \% \text { para } \\
\text { las remesas al exterior } \\
\text { Impuesto adicional } \\
\text { (surtax): } 25 \% \text { sobre las uti- } \\
\text { lidades extraordinarias }\end{array}$ & $\begin{array}{l}\text { Impuesto Especial a } \\
\text { los Hidrocarburos y } \\
\text { Derivados } \\
\text { Impuesto sobre la } \\
\text { comercialización } \\
\text { Impuesto especial } \\
\text { (margen fijo) }\end{array}$ & Sía \\
\hline Chile (cobre) & & $\begin{array}{l}\text { Impuesto sobre los } \\
\text { ingresos, primera } \\
\text { categoría: } 17 \%\end{array}$ & $\begin{array}{l}\text { Impuesto adicional sobre re- } \\
\text { mesas de intereses: } 35 \% \text {; } \\
\text { Para empresas públicas: } \\
\text { impuesto especial del } 40 \% \\
\text { sobre las utilidades ge- } \\
\text { neradas }\end{array}$ & $\begin{array}{l}\text { Impuesto específi- } \\
\text { co sobre el ingreso } \\
\text { operacional de la } \\
\text { actividad minera }\end{array}$ & Sí \\
\hline Colombia (petróleo) & $8-25 \%$ & $35 \%$ & $7 \%$ & $\begin{array}{l}\text { Transporte } \\
\text { Oleoductos }\end{array}$ & Sí \\
\hline Ecuador (petróleo) & $12,5-18,5 \%$ & $25 \%$ & $25 \%$ & & Sí \\
\hline México (petróleo) & & $35 \%$ & $7,7 \%$ & $\begin{array}{l}\text { Impuesto especial } \\
\text { sobre producción y } \\
\text { servicios (IEPS) }\end{array}$ & Sí \\
\hline $\begin{array}{l}\text { Trinidad y Tabago } \\
\text { (petróleo) }\end{array}$ & $\begin{array}{l}10 \% \text { sobre ventas "onsho- } \\
\text { re" y } 12,5 \% \text { sobre ventas } \\
\text { "offshore" } \\
\text { Impuesto adicional sobre } \\
\text { ventas de petróleo crudo } \\
\text { (la tasa varía con el precio } \\
\text { del petróleo) }\end{array}$ & & $\begin{array}{l}\text { Impuesto sobre las utilidades } \\
\text { del petróleo: } 35-42 \% \text { de las } \\
\text { utilidades provenientes de la } \\
\text { producción del petróleo } \\
\text { Impuesto de desempleo: } \\
5 \% \text { de las utilidades pro- } \\
\text { venientes de la producción } \\
\text { de petróleo }\end{array}$ & & \\
\hline
\end{tabular}

Fuente: elaboración propia sobre la base de la legislación de los países.

a Decreto Supremo del $1^{\circ}$ de mayo de 2006: nacionalización de los hidrocarburos.

ingresos que ellos originan. ${ }^{13}$ Estos mecanismos suelen ser: regalías, habitualmente basadas en la producción, lo que permite asegurar al menos un pago mínimo por

\footnotetext{
${ }^{13}$ Además, si bien no va a ser objeto de este informe, es muy importante determinar cuál es el arreglo institucional para repartir estos recursos entre los diferentes niveles de gobierno. Ahmad y Mottu (2002) clasifican la asignación de los recursos provenientes del petróleo en totalmente centralizada, totalmente descentralizada, con separación de fuentes tributarias y con coparticipación de ingresos. En los cuatro países de la región analizados en el trabajo citado (Colombia, Ecuador, México y Rep. Bol. de Venezuela) hay coparticipación de los gobiernos subnacionales en los ingresos provenientes del petróleo. Según ESMAP (2005), se ha observado una marcada tendencia a la descentralización de estos recursos. En Bolivia, Colombia y Ecuador la participación del gobierno central en la recaudación de tales recursos pasó respectivamente de 77\%, 43\% y $100 \%$ en $1997 / 1998$, a $68 \%, 30 \%$ y $97 \%$ en $2000 / 2002$.
}

los recursos minerales; el impuesto sobre los ingresos (muchas veces con alícuotas diferenciadas) y los impuestos sobre las utilidades, aplicables a las empresas dedicadas a la explotación de recursos no renovables. El cuadro 4 resume algunos de los instrumentos recaudatorios utilizados por países de la región.

Este conjunto de tributos ha posibilitado que la recaudación fiscal proveniente de estos sectores capte la evolución de los precios de los productos gravados (gráfico 11).

El importante aumento de los precios registrado en el período 2002-2005, sumado a la incorporación de nuevas medidas tributarias durante el 2005, ha generado un significativo aumento de los recursos fiscales en estos países. Como se verá a continuación, sus autoridades han 
GRÁFICO 11

\section{América Latina y el Caribe (seis países): precios de productos no renovables e ingresos fiscales provenientes de esos productos}

Precio del cobre e ingresos fiscales provenientes del cobre (Chile) (Centavos de dólar por libra y \% del PIB)

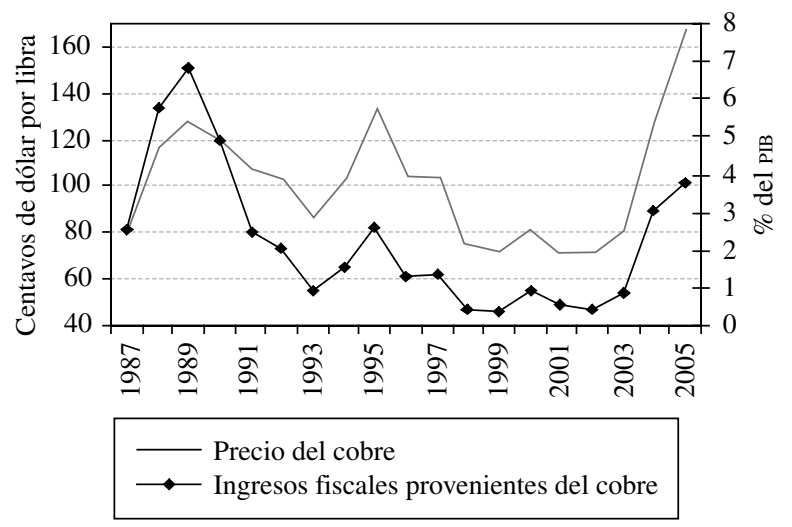

Precio del petróleo e ingresos fiscales provenientes del petróleo (Dólares por barril y \% del PIB)

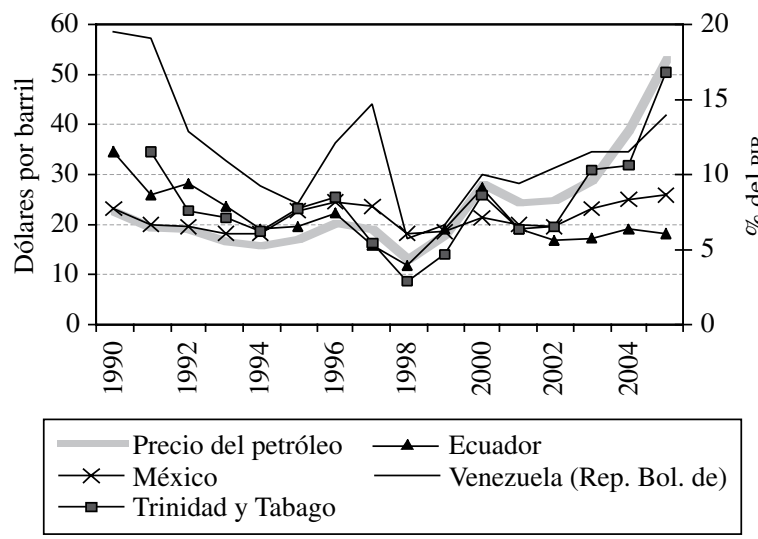

Precio del gas natural e ingresos provenientes de hidrocarburos (Bolivia) (Dólares por millón de BTUa y \% del PIB)
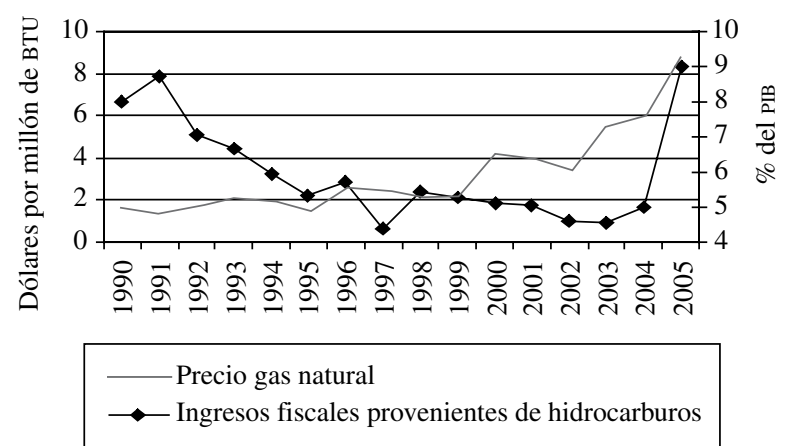

Fuente: elaboración propia con datos oficiales de los países.

a BTU: british thermal unit.

aprovechado este período de bonanza para aplicar nuevos tributos a los sectores que producen minerales y bienes energéticos, especializando aun más sus estructuras tributarias. De los siete países considerados en el gráfico 12, cuatro han elevado sus ingresos fiscales en más de 3\% del PIB: Bolivia (6,7\%), Chile (3,3\%, Trinidad y Tabago $(8,9 \%)$ y la República Bolivariana de Venezuela $(6,4 \%)$.

El importante aumento de los ingresos fiscales provenientes de los bienes no renovables hizo que la carga impositiva sobre los sectores pertinentes alcanzara un nivel comparable con los más altos de la serie. Sin embargo, esta carga no se tradujo en un aumento similar por el lado de los gastos (gráfico 13).
En Bolivia, la mejora de los ingresos fiscales se registró fundamentalmente en el 2005 y se explica, sobre todo, por la aprobación del impuesto directo sobre los hidrocarburos y derivados (IDH), cuya recaudación alcanzó 3,1\% del PIB en ese año, y por el impuesto a las utilidades extraordinarias (Surtax) de las empresas dedicadas a las actividades extractivas, que se decretó en 1994, pero se recaudó por primera vez en el 2005. Esto no significa necesariamente una mejora de las cuentas del gobierno central en la misma proporción, pues el IDH se distribuye entre el Tesoro General de la Nación (42,34\% de lo recaudado) y los departamentos $(57,7 \%)$. Desde el punto de vista de los gastos, el descenso de las 
GRÁFICO 12

América Latina y el Caribe (siete países): variación de los ingresos fiscales entre el 2002 y el 2005

(En porcentajes del producto interno bruto)

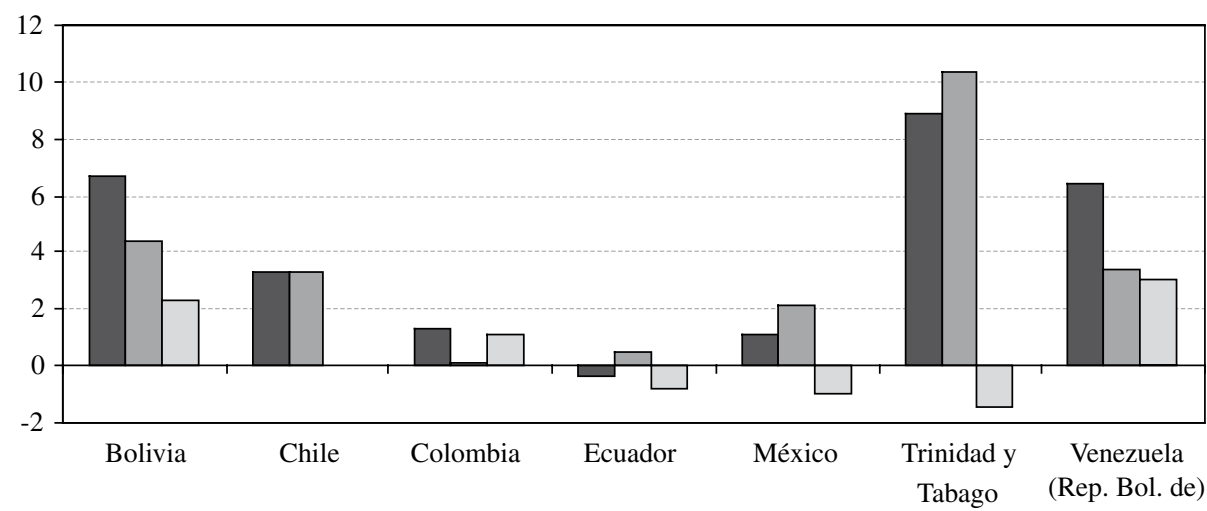

Ingresos totales $\square$ Ingresos provenientes de recursos no renovables $\square$ Otros ingresos

Fuente: elaboración propia con datos de CEPAL-ILPES.

GRÁFICO 13

América Latina (siete países): variación del gasto público entre el 2002 y el 2005

(En porcentajes del producto interno bruto)

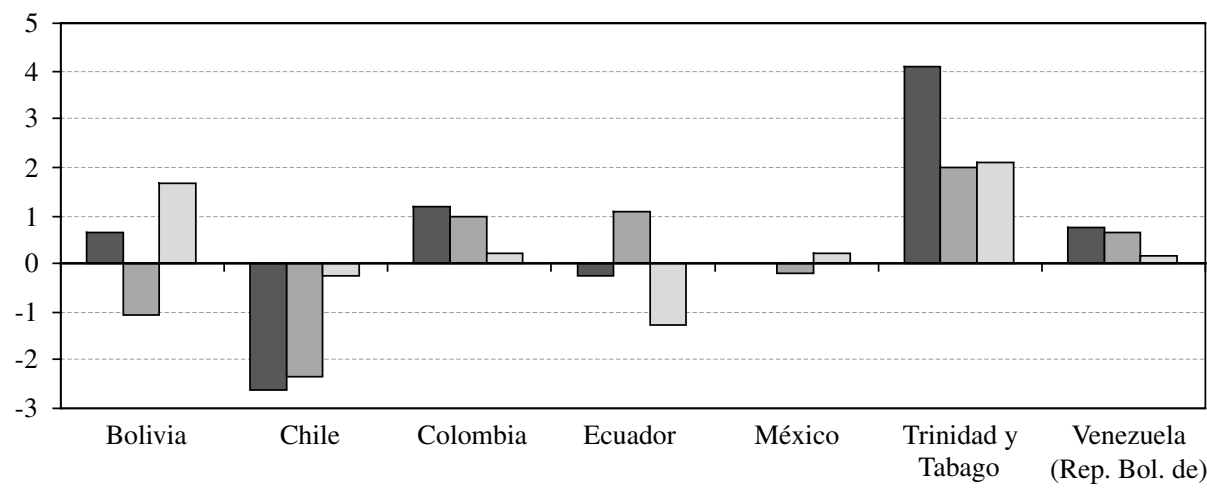

$\square$ Gastos totales $\square$ Gastos corrientes $\square$ Gastos de capital

Fuente: elaboración propia sobre la base de datos de CEPAL-ILPES.

erogaciones corrientes es producto de los programas de austeridad aplicados en los últimos años.

En Chile, el incremento del nivel de actividad y el alza de los precios del cobre y el molibdeno, sumados a cambios legales en la tributación del sector minero (en el 2005 se implantó el impuesto específico a los ingresos operacionales de la minería), se tradujeron en un importante aumento de los ingresos fiscales. La orientación anticíclica de la política fiscal (que se exa- minará más adelante) apunta a un superávit estructural del $1 \%$ del PIB, de modo que los gastos crecieron menos que el PIB, permitiendo mejorar significativamente el resultado fiscal.

En Ecuador, la fuerte mejora de sus términos de intercambio no se reflejó proporcionalmente en mayor holgura fiscal. El aumento de los precios del petróleo influye en el presupuesto público ecuatoriano de distintas maneras. Por un lado, elevan directamente los 
recursos a través de los gravámenes específicos y los ingresos de la Empresa Estatal de Petróleos de Ecuador (Petroecuador). Por otro lado, los mayores costos del petróleo afectan las cuentas públicas, porque los precios internos de los derivados del petróleo están congelados desde el 2003 y una parte importante de la demanda de derivados se cubre con importaciones (pagadas a precios internacionales). Esto hizo que entre el 2003 y el 2005 los ingresos públicos por venta interna de derivados disminuyeran en $1,8 \%$ del PIB.

En Trinidad y Tabago, la política fiscal ha estado orientada en los últimos años a maximizar la recaudación proveniente del sector energético (a expensas del sector no energético) mediante un complejo régimen tributario, que varía según se trate del sector petrolero ${ }^{14} \mathrm{o}$ del gasífero $^{15}$. El crecimiento del sector del gas en este país explica la voluntad del gobierno de llevar a cabo una reforma tributaria para el sector energético en su conjunto, que fue anunciada para el ejercicio fiscal 2005/2006. El significativo incremento de los ingresos logrado permitió aumentar los gastos corrientes y de capital, junto con los aportes al Fondo interino de estabilización del petróleo (FIEP), que se analizará más adelante.

En los últimos años, la República Bolivariana de Venezuela ha llevado adelante numerosas reformas de su estructura tributaria: disminución de la alícuota del impuesto sobre el valor agregado (IVA) y eliminación del impuesto a los activos empresariales en el 2004; aumento de las regalías y el impuesto sobre los ingresos del sector petrolero en el 2005; anuncio de la creación de un nuevo impuesto a la extracción del crudo (impuesto de extracción), y suspensión del cobro del impuesto al débito bancario a principios del 2006. Los mayores recursos fiscales han permitido a las autoridades aplicar una política de gastos expansiva, fundamentalmente a través del Fondo para el Desarrollo Económico y Social del

\footnotetext{
${ }^{14}$ En lo que se refiere al sector petrolero, como sucede en otros países, el régimen tributario distingue entre las fases de exploración, producción, refinación y comercialización. Para las fases de extracción y producción el gobierno percibe ingresos a través de los siguientes instrumentos: royalties (existen dos tasas: $10 \%$ y 12,5\%), un gravamen sobre la producción petrolera y un pequeño impuesto sobre el petróleo (que tiene como objetivo financiar las actividades de regulación del Ministerio de Energía). Los impuestos sobre los ingresos son los siguientes: el impuesto sobre las utilidades del petróleo, a una tasa máxima de $35 \%$ para el petróleo extraído de la tierra y de $42 \%$ para el petróleo extraído del mar; un impuesto de desempleo con una tasa de $5 \%$ de las utilidades, y un impuesto adicional sobre las ventas de petróleo crudo a una tasa que varía según el precio del petróleo.

${ }^{15}$ En lo que se refiere al sector del gas, las empresas pagan un royalty a una tasa negociada con el gobierno. En cuanto a gravámenes sobre los ingresos, las empresas tributan el impuesto tradicional sobre las utilidades $(35 \%)$ y un pequeño impuesto sobre el petróleo.
}

País (FONDESPA) cuyos ingresos provienen de las ventas de petróleo realizadas por PDVSA y que no se reflejan en los datos correspondientes al gobierno central.

Los positivos resultados fiscales constituyen uno de los factores que han permitido a estos países bajar su deuda pública como proporción del PIB. En el período 2003-2005 Bolivia redujo su deuda en 10,4\% del PIB, Chile en 5,6\%, Colombia en 3,8\%, Ecuador en $2,7 \%$, México en $1,9 \%$ y la República Bolivariana de Venezuela en 12,2\% (CEPAL, 2006). Una gran parte de esta reducción, salvo en Bolivia, se explica por superávit primarios en el período 2002-2005. Esto remite a otra cuestión, que cobra importancia en períodos de auge de precios y que tiene que ver con el uso adecuado de los excedentes fiscales generados y la forma de evitar los problemas macroeconómicos asociados a estos períodos de bonanza.

Se plantean así dos problemas que no siempre pueden ser resueltos conjuntamente. Uno es el de estabilizar el gasto, disociando su evolución de los aumentos de recursos y permitiendo transformar tal aumento en excedente fiscal. El otro es el de manejar correctamente este excedente fiscal y los activos resultantes.

El primer problema se relaciona con el papel que debiera desempeñar la política fiscal en la estabilización de la economía. En este sentido, los países de la región han buscado diversas maneras de cumplir con la recomendación básica que suele hacerse cuando la economía atraviesa por un período de bonanza, que es la de moderar la actividad mediante la restricción del gasto público. Con este propósito, en los últimos años se ha seguido una política fiscal discrecional menos expansiva, como se subrayó en los párrafos anteriores, y se han incluido nuevas reglas fiscales.

En la región se ha hecho intenso uso de las reglas fiscales desde la segunda mitad del decenio de 1990. Estas reglas, cuyo objetivo inicial fue el de mejorar la solvencia de las cuentas públicas, ${ }^{16}$ han permitido en algunos casos separar la evolución de los recursos del desempeño del gasto (cuadro 5).

Estas reglas fiscales han tomado diversas formas que van desde los límites cuantitativos al saldo, gasto y endeudamiento, a la conformación de fondos contingentes o de estabilización.

En Ecuador, con el objetivo de mejorar la sostenibilidad fiscal, se aprobó la Ley Orgánica de Responsabilidad,

\footnotetext{
${ }^{16}$ En aquellos países más descentralizados de la región, como Argentina, Brasil y Colombia, uno de los objetivos principales de estas normas fue el de coordinar la política fiscal (gasto, déficit y endeudamiento) entre los diferentes niveles de gobierno.
} 
América Latina y el Caribe: reglas fiscales vigentes

\begin{tabular}{|c|c|c|c|c|c|c|}
\hline & País & $\begin{array}{c}\text { Fecha de } \\
\text { implementación }\end{array}$ & Cobertura & Tipo & Reglas adicionales & $\begin{array}{c}\text { Estado } \\
\text { legal }\end{array}$ \\
\hline \multirow[t]{8}{*}{ Regla de saldo } & Argentina & 2004 & $\begin{array}{l}\text { Federal y } \\
\text { subnacional }\end{array}$ & $\begin{array}{l}\text { Crecimiento nominal del } \\
\text { gasto primario no podrá } \\
\text { superar la tasa de aumento } \\
\text { nominal del PIB }\end{array}$ & & Ley \\
\hline & Brasil & 2001 & $\begin{array}{l}\text { Federal y } \\
\text { subnacional }\end{array}$ & $\begin{array}{l}\text { Equilibrio corriente (subna- } \\
\text { cional); superávit primario } \\
\text { (federal) }\end{array}$ & $\begin{array}{l}\text { Límites de gasto salarial } \\
\text { (porcentaje del total) }\end{array}$ & Ley \\
\hline & Chile & 2006 & Central & $\begin{array}{l}\text { Superávit global estructural } \\
\text { (1\% del PIB) }\end{array}$ & $\begin{array}{l}\text { Fondo de Reserva de Pensio- } \\
\text { nes (FRP) } \\
\text { Fondo de Estabilización Eco- } \\
\text { nómica y Social (FEES) }\end{array}$ & Ley \\
\hline & Colombia & 2001 & $\begin{array}{l}\text { Gobiernos } \\
\text { subnacionales }\end{array}$ & Equilibrio corriente & $\begin{array}{l}\text { Fondo Nacional del Café } \\
\text { (FNC); } \\
\text { Fondo de Ahorro y Estabili- } \\
\text { zación Petrolera (FAEP) }\end{array}$ & Ley \\
\hline & Ecuador & 2005 & $\begin{array}{l}\text { Federal y } \\
\text { subnacional }\end{array}$ & $\begin{array}{l}\text { Crecimiento real del gasto } \\
\text { corriente no podrá superar } \\
\text { el } 3,5 \%\end{array}$ & $\begin{array}{l}\text { Fondo de Estabilización Pe- } \\
\text { trolera (FEP); } \\
\text { Fondo de Ahorro y Contin- } \\
\text { gencias (FAC) }\end{array}$ & Ley \\
\hline & México & 2006 & $\begin{array}{l}\text { Federal y } \\
\text { subnacional }\end{array}$ & Equilibrio corriente & $\begin{array}{l}\text { Fondo de Estabilización de los } \\
\text { Ingresos Petroleros (FEIP) }\end{array}$ & Ley \\
\hline & Perú & 2003 & Nacional & $\begin{array}{l}\text { Déficit inferior a } 1 \% \text { del } \\
\text { PIB; crecimiento real del } \\
\text { gasto primario no superior } \\
\text { a } 3 \% \text { por año }\end{array}$ & $\begin{array}{l}\text { Fondo de Estabilización } \\
\text { Fiscal }\end{array}$ & Ley \\
\hline & $\begin{array}{l}\text { Venezuela } \\
\text { (Rep. Bol. de) }\end{array}$ & 2000 & Nacional & Equilibrio corriente & $\begin{array}{l}\text { Fondo de Estabilización Ma- } \\
\text { croeconómica (FEM) }\end{array}$ & Ley \\
\hline \multirow[t]{4}{*}{ Regla de deuda } & Argentina & 2004 & $\begin{array}{l}\text { Gobiernos } \\
\text { subnacionales }\end{array}$ & $\begin{array}{l}\text { Límites anuales de endeuda- } \\
\text { miento, de manera tal que los } \\
\text { servicios no superen el } 15 \% \\
\text { de los recursos corrientes }\end{array}$ & & Ley \\
\hline & Brasil & 2001 & $\begin{array}{l}\text { Gobiernos } \\
\text { subnacionales }\end{array}$ & $\begin{array}{l}\text { Límites anuales de endeu- } \\
\text { damiento }\end{array}$ & & Ley \\
\hline & Colombia & 1997 & $\begin{array}{l}\text { Gobiernos } \\
\text { subnacionales }\end{array}$ & $\begin{array}{l}\text { Límite al endeudamiento, de } \\
\text { acuerdo con indicadores de } \\
\text { solvencia y liquidez }\end{array}$ & & Ley \\
\hline & Ecuador & 2005 & $\begin{array}{l}\text { Federal y } \\
\text { subnacional }\end{array}$ & $\begin{array}{l}\text { Cronograma de reducción } \\
\text { de deuda, hasta alcanzar } \\
40 \% \text { del PIB }\end{array}$ & $\begin{array}{l}\text { Límites al endeudamiento } \\
\text { de gobiernos subnacionales } \\
\text { (acervo, flujo y garantías) }\end{array}$ & Ley \\
\hline
\end{tabular}

Fuente: elaboración propia con datos de ILPES (2004) y Kopits (2004), y con información oficial.

Estabilidad y Transparencia Fiscal (aprobada en el 2002 y modificada en el 2005) que establece un límite para el aumento de los gastos corrientes de 3,5\%, en términos reales. ${ }^{17}$

\footnotetext{
${ }^{17}$ Para más detalles véase Almeida, Gallardo y Tomaselli (2006).
}

En Chile, las autoridades han aplicado a partir del 2001 una regla de política fiscal basada en el cumplimiento de un superávit estructural equivalente a un $1 \%$ del producto interno bruto. ${ }^{18} \mathrm{El}$ balance estructural

${ }^{18}$ Respecto a las potencialidades y dificultades en la implementación de este tipo de reglas en Chile, véanse Marcel, Tokman y otros (2001), Tapia (2003) y LeFort (2006). 
del gobierno central refleja el resultado presupuestario que se obtendría cada año, si el producto evolucionara de acuerdo con su tendencia y si el precio del cobre y el molibdeno fuera igual al proyectado. El objetivo es ajustar el resultado fiscal, aislándolo del efecto que tienen en los ingresos las fluctuaciones del PIB y del precio del cobre y el molibdeno. Para su elaboración deben estimarse dos variables: el precio de largo plazo del cobre y la tasa de crecimiento del PIB tendencial. Ambas son estimadas por un comité de expertos durante la preparación del presupuesto.

Otros mecanismos que han cobrado particular importancia en la región han sido los fondos contingentes relacionados con la explotación de los recursos no renovables. ${ }^{19}$ De acuerdo con su objetivo fundamental, se les suele clasificar en fondos de estabilización y fondos de ahorro. Los fondos de estabilización buscan atenuar el impacto de las fluctuaciones de los ingresos sobre el gasto público. Por su parte, los fondos de ahorro persiguen crear una reserva de riqueza, pensando en las futuras generaciones que podrían beneficiarse con parte de los recursos recaudados por la utilización de yacimientos de productos agotables; en otras palabras, pretenden poner a resguardo un monto de activos para que esas generaciones disfruten parte de lo extraído en el presente. No obstante, como hicieron notar Jiménez y Tromben (2006), los fondos creados en los últimos años se han regido por criterios más cercanos a la estabilización que al ahorro.

Si bien existen algunos fondos de estabilización muy antiguos en la región (el Fondo del Café en Colombia data de 1940), en los últimos años ha habido un nuevo impulso para crear estos mecanismos: en Chile, el Fondo de Compensación del Cobre (FCC), creado en 1985, activado en 1987 y reemplazado por el Fondo de Estabilización Económica y Social en el 2006; en Colombia, el Fondo de Ahorro y Estabilización Petrolera (FAEP), creado en 1995; en Ecuador, el Fondo de Estabilización, Inversión Social y Productiva y Reducción del Endeudamiento Público (FEIREP), creado en 2002 y reemplazado por el Fondo de Ahorro y Contingencias en el 2005; en México, el Fondo de Estabilización de los Ingresos Petroleros (FEIP), creado en el 2000; en la República Bolivariana de Venezuela, el Fondo de Estabilización Macroeconómica (FEM), creado en el 2004 en reemplazo del antiguo Fondo de Inversión para la Estabilización Macroeconómica (FIEM), establecido en 1998.

\footnotetext{
${ }^{19}$ Véase un análisis exhaustivo de la experiencia con estos fondos en América Latina en Jiménez y Tromben (2006).
}

Como se observa en el cuadro 6, estos fondos tienen objetivos diversos y han registrado numerosos cambios desde su creación. Entre las diferencias que existen en el diseño de estos fondos cabe subrayar: i) la variable que se toma como referencia (en Chile un comité de expertos establece anualmente un precio base, en Ecuador el FEIREP toma dos precios de referencia, en México el precio de referencia se incluye en la Ley de Ingresos de la Federación, en Colombia y la República Bolivariana de Venezuela la referencia no es un precio sino las fluctuaciones de los ingresos fiscales), y ii) la existencia o inexistencia de preasignaciones presupuestarias, lo que se detallará más adelante. Como características comunes de los fondos, puede señalarse que en todos los casos se definen reglas de ahorro de aquellos ingresos que superan el valor de referencia de la variable utilizada como objetivo, y no un límite al gasto.

El desempeño de los diversos fondos ha tenido evoluciones diferentes. En Chile, el comportamiento del Fondo de Compensación del Cobre (FCC) varió en distintos períodos. En 1987-1991, el precio del cobre registró valores muy altos, lo que se tradujo en aportes crecientes al fondo, y los giros fueron casi equivalentes a los aportes, lo que significa que las autoridades usaron los recursos disponibles. En esos años se constituyó el Fondo de Estabilización del Precio del Petróleo (FEPP). ${ }^{20}$ En el período 1992-1997 el precio del cobre mostró gran volatilidad; sin embargo, las autoridades no hicieron uso de los recursos acumulados en el FCC. En el período 1998-2003 se registró una fuerte caída de dicho precio, con lo cual los aportes al fondo fueron menores y llegaron a ser nulos en los años 2000 y 2003 , aunque se recuperaron en los años 2004 y 2005.

En Colombia, a partir de 1995 comenzó a operar el FAEP. Según algunos autores, pese a que este fondo no logró el objetivo de contribuir a una mayor estabilidad fiscal y macroeconómica, ha servido como mecanismo para controlar los gastos de las entidades territoriales (departamentos y municipios) que reciben ingresos petroleros.

En México, si bien la creación del FEIP es demasiado reciente como para formular juicios, los bajos saldos

\footnotetext{
${ }^{20}$ El Fondo de Estabilización del Precio del Petróleo (FEPP) es un mecanismo que define el porcentaje de las alzas en el precio del crudo importado que debería traspasarse al público. Su objetivo es mantener cierta estabilidad en los precios de los derivados del petróleo en el mercado nacional chileno. El FEPP fue creado en enero de 1991 (Ley 19.030) y se constituyó con un monto inicial de 200 millones de dólares provenientes, a modo de préstamo, del Fondo de Compensación del Cobre.
} 


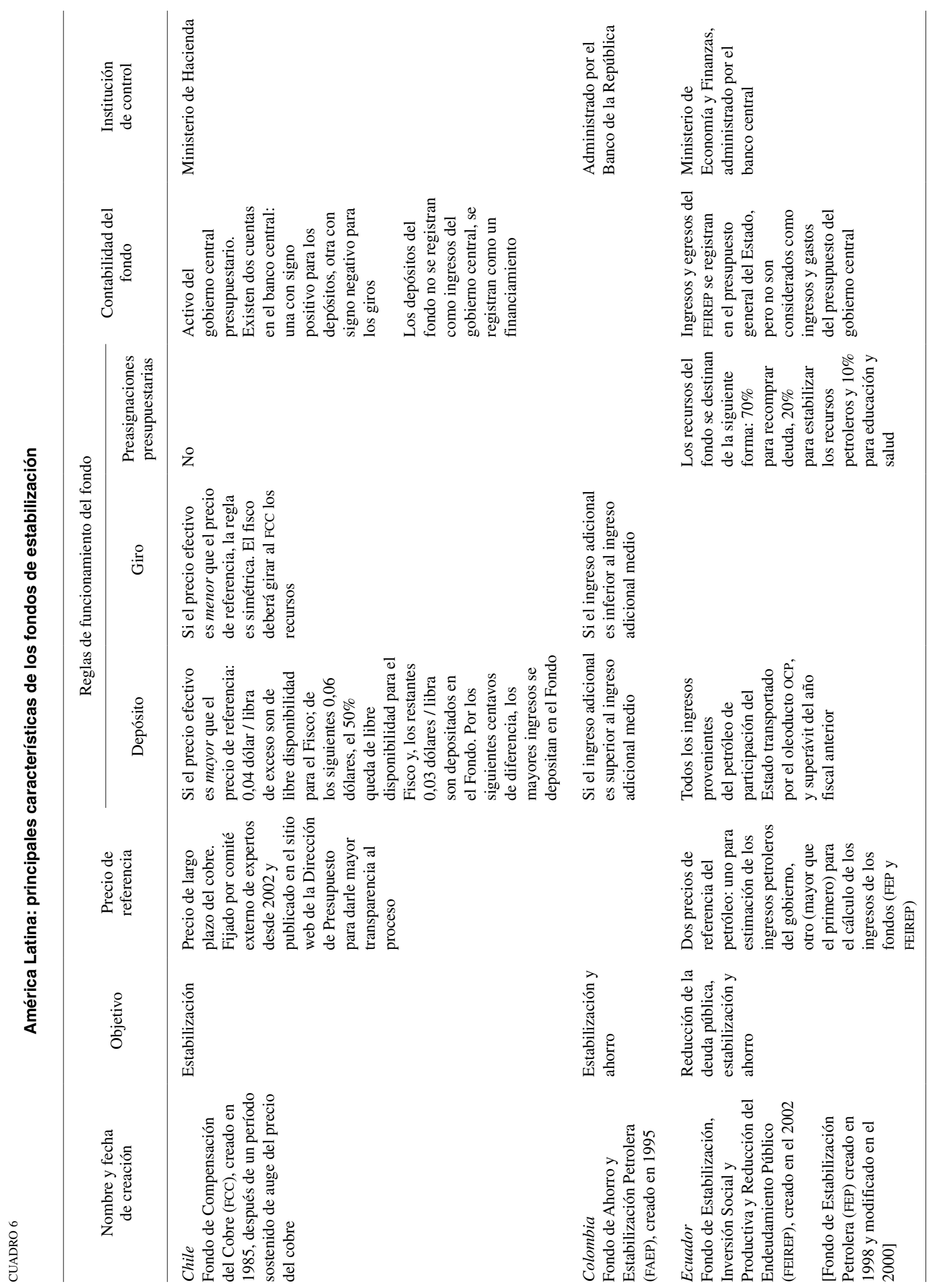




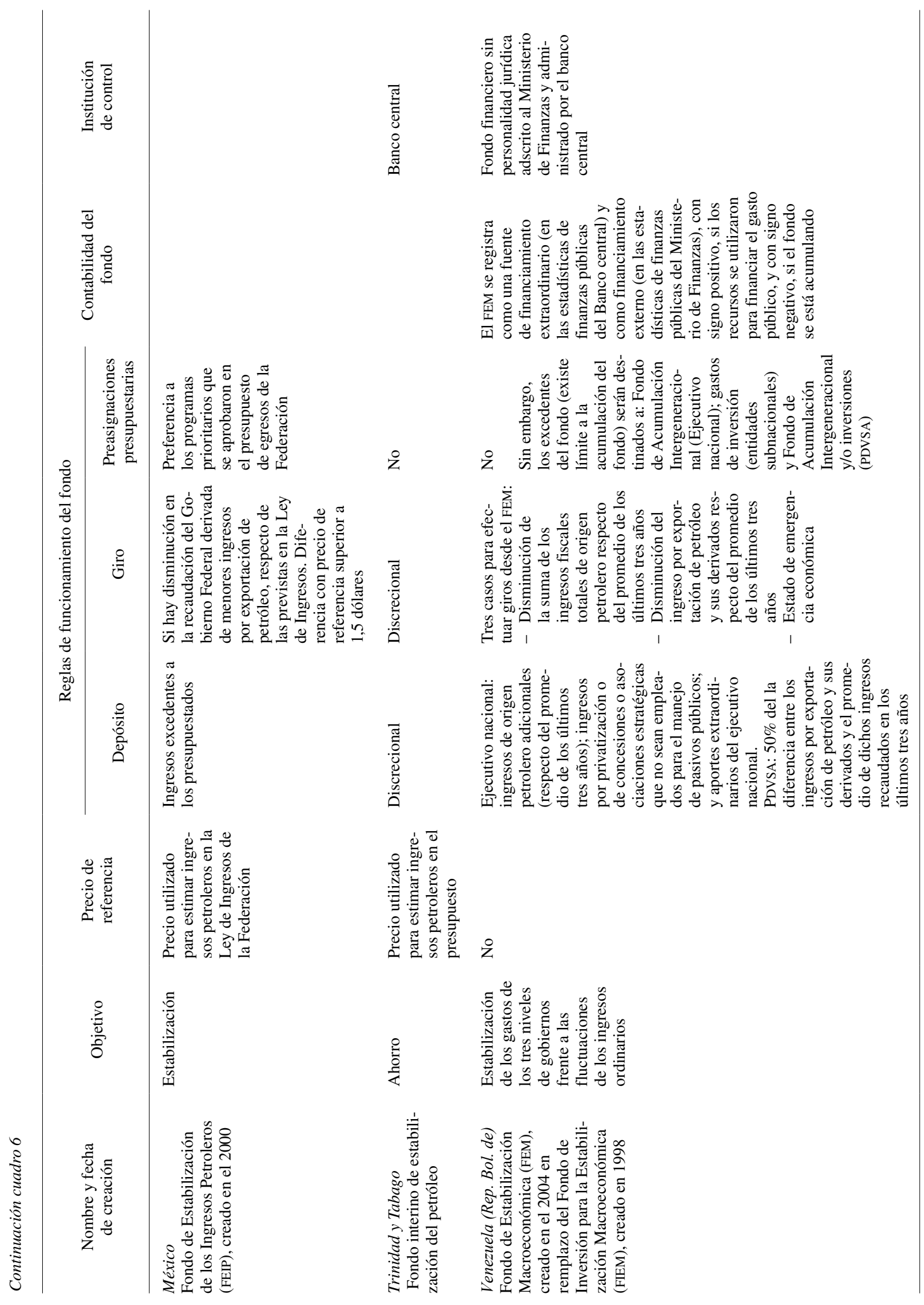


acumulados con respecto a los recursos totales sugieren que su capacidad de estabilización es reducida.

En la República Boliviariana de Venezuela, el FIEM, que se creó en 1998 y fue reemplazado en el 2004 por el FEM, es de los fondos que más acumulación muestran (5,3\% del PIB en el 2001). Debe destacarse, sin embargo, que ha habido sucesivas modificaciones a sus reglas de funcionamiento y utilización con fines distintos a los originalmente estipulados.

En Trinidad y Tabago, el Fondo interino de estabilización del petróleo (FIEP) se creó en el 2000 como un mecanismo para ahorrar el exceso de ingresos fiscales generado por la diferencia entre el precio de referencia del petróleo utilizado para calcular los ingresos y el precio efectivo del petróleo. A diferencia de los demás fondos presentes en la región, el FIEP fue creado por la ley de presupuesto del año fiscal 2000/2001; sin embargo, ninguna ley establece las reglas para su funcionamiento (reglas de giro y depósito, gestión del fondo). A pesar de ello, y como se verá más adelante, el FIEP es el fondo que ha acumulado más recursos como proporción del PIB. La ley de presupuesto del año fiscal 2005/2006 contempla la transformación de este fondo (mediante una ley) en un Fondo de estabilización patrimonial (Heritage Stabilization Fund), que tendría tres componentes: un componente de estabilización, otro de patrimonio para las generaciones futuras y un último componente de inversión e infraestructura.

El segundo problema es el de determinar cuál debiera ser el correcto manejo de los excedentes fiscales en períodos de auge de precios En los últimos años ha habido una creciente preocupación por la forma de usar los excedentes fiscales generados por los mejores precios de los productos no renovables. A medida que aumentan los ingresos fiscales, y los países logran estabilizar el gasto fiscal frente a las fluctuaciones de corto plazo de los ingresos provenientes de productos no renovables, se impone preguntarse cómo se debieran utilizar esos excedentes.

Como muestra el cuadro 6, los recursos que ingresan a los fondos están mayoritariamente preasignados. La existencia de preasignaciones o asignaciones específicas puede tornar más rígido el proceso presupuestario. $\mathrm{Si}$ bien en el caso de Chile no hay preasignación, los fondos vigentes en Ecuador, México y la República Bolivariana de Venezuela tienen algún tipo de preasignación. En el caso de Ecuador, la totalidad de los recursos de la cuenta especial denominada Reactivación Productiva y Social, del Desarrollo Científico y Tecnológico y de la Estabilización Fiscal (CEREP), que reemplazó al FEIREP, está asignada de la siguiente manera: 35\% para líneas de crédito, cancelación de la deuda con el Instituto Ecuatoriano de Seguridad Social, recompra de deuda externa y ejecución de proyectos de infraestructura; $30 \%$ para proyectos de inversión social; 5\% para la investigación científico-tecnológica orientada al desarrollo; 5\% para el mejoramiento de la red vial; 5\% para reparación ambiental y social, y el $20 \%$ restante para estabilizar los ingresos petroleros.

Las altas preasignaciones de los Fondos sumadas a los sucesivos cambios de reglas han hecho que estos tengan una baja capacidad para acumular saldos. Como se observa en el cuadro 7, con la excepción de Trinidad y Tabago, el aumento que se registra en los precios de los productos no renovables desde el 2002 y que impacta en los ingresos fiscales no ha significado un incremento concomitante en los saldos de los fondos de estabilización existentes en la región. ${ }^{21}$

Con miras a lograr que se utilicen adecuadamente los excedentes fiscales generados, en el 2006 tanto Chile como México establecieron mecanismos para reglamentar su uso. En Chile se aprobó la Ley de Responsabilidad Fiscal, que reglamenta la regla de balance estructural y el manejo de los activos fiscales que exceden el nivel de gasto fijado por la la regla de balance estructural. Para ello se crearon dos fondos: el Fondo de Reserva de Pensiones (FRP) y el Fondo de Estabilización Económica y Social (FEES). El primero está destinado a complementar el financiamiento de las obligaciones fiscales derivadas de la garantía estatal de pensiones mínimas y estará constituido fundamentalmente por un aporte del superávit fiscal con un tope del $0,5 \%$ del PIB. El segundo se alimentará de los recursos del Fondo de Compensación del Cobre (al cual reemplaza) y de los recursos provenientes de superávit fiscales mayores al $1 \%$ del PIB, restados los aportes al FRP; los recursos del FEES se destinarán a financiar gasto social e inversión pública.

Por el lado de México, en mayo de 2006 se aprobó la Ley Federal de Presupuesto y Responsabilidad Hacendaria, que reglula la utilización de los recursos fiscales excedentes para evitar que se destinen al gasto corriente. Con este fin se constituyen fondos de compensación, los que deben acumular ahorros para ser utilizados cuando caigan los precios del petróleo. En

\footnotetext{
${ }^{21}$ Rigobón (2006) resume los problemas de este tipo de fondos de la siguiente manera: por un lado, están los relacionados con la apropiabilidad, que se refiere a la posibilidad de usar o gastar los recursos ahorrados más allá de su regla de funcionamiento; por el otro, están aquellos relacionan con la gobernabilidad, que se relaciona con la tendencia a crear numerosos fondos para alcanzar un solo objetivo.
} 
América Latina y el Caribe (seis países): saldos a fin de año de los fondos de estabilización, 1996-2005

(En porcentajes del producto interno bruto)

\begin{tabular}{lccccccccccc}
\hline & 1996 & 1997 & 1998 & 1999 & 2000 & 2001 & 2002 & 2003 & 2004 & 2005 \\
\hline Chile & 2,3 & 2,3 & 2,0 & 1,5 & 1,0 & 0,9 & 0,4 & 0,1 & 0,2 & 0,8 \\
Colombia & 0,0 & 0,1 & 0,2 & 0,6 & 1,7 & 1,7 & 1,7 & 1,4 & 1,2 & 1,6 \\
Ecuador & & & & & & & & 0,3 & 0,4 & 1,1 \\
México & & & & & 0,2 & 0,1 & 0,0 & 0,1 & 0,2 & 0,2 \\
Trinidad y Tabago & & & & & 1,7 & 1,7 & 2,3 & 3,9 & 4,5 & 5,4 \\
Venezuela (Rep. Bol. de) & & & & 0,2 & 4,0 & 5,3 & 3,7 & 0,8 & 0,7 & 0,5 \\
\hline
\end{tabular}

Fuente: CEPAL, sobre la base de información oficial. La información sobre el fondo de Ecuador para el 2005 corresponde al saldo al momento de la liquidación del fondo (7 de octubre de 2005).

una primera etapa y hasta que estos fondos alcancen niveles adecuados de reserva, los ingresos excedentes del petróleo se asignarán de la siguiente manera: $25 \%$ al Fondo de Estabilización de los Ingresos de las Entidades Federativas, que servirá para compensar disminuciones de la recaudación coparticipable efectiva con relación a la estimada en el presupuesto; $25 \%$ al Fondo de Estabilización para la Inversión en Infraestructura de Petróleos Mexicanos, que servirá para compensar dis- minuciones en los ingresos propios de PEMEX; $40 \%$ al Fondo de Estabilización de los Ingresos Petroleros, que servirá para compensar disminuciones de los ingresos petroleros del gobierno federal, y $10 \%$ a proyectos de inversión en infraestructura de las entidades federativas. En una segunda etapa los destinos de los recursos serán los siguientes: $50 \%$ para inversión en infraestructura, $25 \%$ para inversión en PEMEX y 25\% para el sistema de pensiones.

\section{V}

\section{Algunas reflexiones finales}

A lo largo de este artículo se ha destacado que los países que se especializan en productos no renovables distan mucho de ser un grupo homogéneo. Hay entre ellos importantes diferencias respecto al producto no renovable en que se han especializado; la importancia de este producto en la economía, la variación de su precio, el tamaño de los yacimientos, el impacto fiscal de los ingresos por su explotación, el grado de diversificación de la estructura tributaria, la composición del gasto y el nivel de deuda, todos ellos de suma importancia para diseñar la política fiscal adecuada. Por eso, al analizarlos en su conjunto es preciso no descuidar los aspectos particulares de cada caso. No obstante, si se compara el desempeño fiscal de este conjunto de países con el de los demás países de la región, se observan algunas notas distintivas, sobre todo, en cuanto a la solvencia y la volatilidad de sus cuentas públicas.
Por otro lado, debe hacerse hincapié en que, pese al importante esfuerzo de diversificación de las exportaciones que ha desplegado la región en los últimos años, se observa en muchos países latinoamericanos que un solo producto ha mantenido una significativa participación en sus exportaciones totales. Este hecho, sumado a los mayores precios de los bienes energéticos y minerales, se ha traducido en una fuerte mejora de los términos de intercambio de los países especializados en estos bienes.

La estructura impositiva de tales países, fortalecida por la inclusión de nuevos instrumentos tributarios, así como la evolución de los precios en los últimos años, les permitió aumentar marcadamente su recaudación fiscal, concentrando aún más su sistema tributario en los sectores pertinentes. A diferencia de otros episodios anteriores, este aumento de los ingresos no trajo consigo un aumento equivalente del gasto. Esto se debió 
a decisiones fiscales no expansivas y a la introducción de nuevas instituciones fiscales, lo que permitió a estos países generar saldos fiscales positivos.

La rica experiencia reciente de la región en el diseño y puesta en práctica de diversas instituciones fiscales, ya sea reglas sobre el gasto o sobre la deuda, o fondos contingentes, no permite extraer conclusiones lineales. En el caso de los fondos, no es fácil efectuar una evaluación concluyente, si se tiene en cuenta que en México y la República Bolivariana de Venezuela estos mecanismos solo tienen cuatro años de antigüedad y que en Ecuador el fondo establecido en el 2002 duró solamente tres años. Sin embargo, por algunas características de sus diseños, las numerosas preasignaciones y los sucesivos cambios de reglas, estos fondos han mostrado una baja acumulación de saldos, lo que plantea dudas sobre su capacidad para cumplir con los objetivos enunciados.

La situación descrita intensificó el debate en estos países sobre el uso adecuado de los excedentes fiscales.
En virtud de este debate, tanto Chile como México han incorporado nuevos instrumentos para reglamentar el manejo de los activos fiscales excedentes.

En definitiva, el desempeño fiscal de los últimos años sugiere que hay espacio para perfeccionar las iniciativas fiscales con objetivos estabilizadores que se han adoptado en el último tiempo. Como ya se resaltó a lo largo de este ensayo, los problemas de solvencia, volatilidad y relación con el ciclo económico no son monopolio de los países concentrados en la exportación de productos no renovables, de modo que la discusión sobre políticas fiscales estabilizadoras excede al grupo de países aquí analizados. No obstante, en el debate sobre el uso adecuado de los excedentes fiscales y tratándose de países especializados en productos agotables, habría que incorporar con más fuerza consideraciones de equidad intergeneracional que permitan crear una reserva de recursos para las generaciones futuras.

\section{Bibliografía}

Ahmad, E. y E. Mottu (2002): Oil Revenue Assignments: Country Experiences and Issues, Working Paper, $\mathrm{N}^{\circ}$ 02/203, Washington, D.C., Fondo Monetario Internacional.

Alesina, A. y G. Tabellini (2005): Why is Fiscal Policy Often Procyclical?, NBER Working Paper, No 11600 , Cambridge, Massachusetts, National Bureau of Economic Research, septiembre.

Almeida, M., V. Gallardo y A. Tomaselli (2006): Gobernabilidad fiscal en Ecuador, serie Gestión pública, No 57, LC/L.2529-P, Santiago de Chile, Instituto Latinoamericano y del Caribe de Planificación Económica y Social (ILPES). Publicación de las Naciones Unidas, $\mathrm{N}^{\circ}$ de venta: S.06.II.G.56.

Catão, L. y B. Sutton (2002): Sovereign Defaults: the Role of Volatility, Working Paper, $\mathrm{N}^{\circ} 02 / 149$, Washington, D.C., Fondo Monetario Internacional.

CEPAL (Comisión Económica para América Latina y el Caribe) (2005a): Estudio económico de América Latina y el Caribe, 2004-2005, LC/G.2279-P, Santiago de Chile, agosto. Publicación de las Naciones Unidas, $\mathrm{N}^{\circ}$ de venta: S.05.II.G.2.

(2005b): Balance preliminar de las economías de América Latina y el Caribe, 2005, LC/G.2292-P, Santiago de Chile, diciembre. Publicación de las Naciones Unidas, $\mathrm{N}^{\mathrm{o}}$ de venta: S.05.II.G.108.

(2006): Estudio económico de América Latina y el Caribe, 2005-2006, LC/G.2314-P, Santiago de Chile. Publicación de las Naciones Unidas, $\mathrm{N}^{\mathrm{o}}$ de venta: S.06.II.G.2.

ESMAP (Programa de Asistencia para la Gestión en el Sector de la Energía) (2005): Comparative Study on the Distribution of Oil Rental in Bolivia, Colombia, Ecuador and Peru, Washington, D.C., Banco Mundial, agosto.

Gavin, M., R. Hausmann y otros (1996): Managing Fiscal Policy in Latin America and the Caribbean: Volatility, Procyclicality and Limited Creditwothiness, Working Paper, $\mathrm{N}^{\circ} 326$, Washington, D.C., Banco Interamericano de Desarrollo.

Gavin, M. y R. Perotti (1997): Fiscal policy in Latin America, en B. Bernanke y J. Rotemberg (comps.), NBER Macroeconomics Annual 1997, Cambridge, Massachusetts, The MIT Press.
Halperin Donghi, T. (1990): Historia contemporánea de América Latina, Madrid, Alianza Editorial.

ILPES (Instituto Latinoamericano y del Caribe de Planificación Económica y Social) (2004): Panorama de la gestión pública, LC/IP/L.243, Santiago de Chile, mayo.

Jiménez, J.P. y V. Tromben (2006): Política fiscal en países especializados en productos no renovables en América Latina, serie Macroeconomía del desarrollo, No 46, LC/L.2521-P, Santiago de Chile, Comisión Económica para América Latina y el Caribe (CEPAL). Publicación de las Naciones Unidas, $\mathrm{N}^{\circ} \mathrm{de}$ venta: S.06.II.G.48.

Kaminsky, G., C. Reinhart y C. Vegh (2004): When It Rains: Procyclical Capital Flows and Macroeconomic Policies, NBER Working Paper, No 10780, Cambridge, Massachusetts, National Bureau of Economic Research.

Kaplinsky, R. (2005): Revisiting the revisited terms of trade: Will China make a difference?, Sussex, Instituto de Estudios para el Desarrollo, Universidad de Sussex, marzo.

Kopits, G. (2004): Rules-based Fiscal Policy in Emerging Markets: Background, Analysis and Prospects, Nueva York, Palgrave Macmillan.

LeFort, G. (2006): Política fiscal con meta estructural en la experiencia chilena, documento presentado en la segunda reunión anual del grupo latinoamericano de especialistas en manejo de deuda pública (LAC Debt Group), Cartagena de Indias, Colombia.

Marcel, M., M. Tokman y otros (2001): Balance estructural del gobierno central. Metodología y estimaciones para Chile: 1987-2000, Estudios de finanzas públicas, Santiago de Chile, Ministerio de Hacienda de Chile.

Martner, R. y V. Tromben (2003): Tax reforms and fiscal stabilization in Latin America, documento presentado en el Taller sobre política tributaria (Perugia, Italia, 3 al 5 de abril de 2003), Santiago de Chile.

Ovalle, A. (2006): América Latina: evolución del índice de precios de los principales productos de exportación, 19802005 , documento de proyectos, $N^{\circ} 71$, LC/W.71, Santiago 
de Chile, Comisión Económica para América Latina y el Caribe (CEPAL).

Prebisch, R. (1949): El desarrollo económico de la América Latina $y$ algunos de sus principales problemas, E/CN.12/89, Santiago de Chile, Comisión Económica para América Latina y el Caribe (CEPAL).

Rigobón, R. (2006): Fiscal response to revenue uncertainty, documento presentado en la Fundación CIDOB (Barcelona, 6 y 7 de octubre de 2006).
Talvi, E. y C.A. Vegh (2000): Tax Base Variability and Procyclical Fiscal Policy, NBER Working Paper, No 7499, Cambridge, Massachusetts, National Bureau of Economic Research.

Tapia, H. (2003): Balance estructural del gobierno central de Chile: análisis y propuestas, serie Macroeconomía del Desarrollo, No 25, LC/L.1938-P, Santiago de Chile, Comisión Económica para América Latina y el Caribe (CEPAL). Publicación de las Naciones Unidas, $\mathrm{N}^{\mathrm{o}}$ de venta: S.03.II.G.97. 